Sandra Hoffmann*, Alan Krupnick and Ping Qin

\title{
Building a Set of Internationally Comparable Value of Statistical Life Studies: Estimates of Chinese Willingness to Pay to Reduce Mortality Risk
}

\begin{abstract}
This study is the eighth in a series of stated-preference studies designed to enhance the basis for international benefits transfer of value of statistical life (VSL) estimates. The series has fielded essentially similar stated-preference surveys in Canada, China, France, Italy, Japan, Mongolia, the United Kingdom, and the United States. This Chinese study estimates the willingness to pay for contemporaneous and future mortality risk reductions of residents of Shanghai, Jiujiang, and Nanning, China using a stated-preference payment-card survey. The pooled VSL for a contemporaneous reduction in annual mortality risk reduction of 5 in 10,000 is about 1.47 million 2009 yuan (\$614,805 U.S. \$2016), with income elasticities of 0.2 to 0.25 . This VSL estimate is at the lower end of estimates from the eight countries, between those from Mongolia and Japan, and in the mid-range of estimates of willingness to pay (WTP) for mortality risk reductions as a percentage of household income. We find lower discount rates in the Mongolia, Japan, and China studies than in those fielded in North America or Europe. The study also explores the relative performance of dichotomous choice and stated-preference card elicitation methods in a middle income country setting and develops a computerized "payment card" that allows testing for anchoring. Implicit transfer elasticities across countries, calculated using the VSLs we estimate and each country's income, relative to those of the United States, yields estimates of $0.88-0.95$ for the lower income countries. These compare with the default assumption of 1.0 or assumed elasticities of 1.2 for developing countries.
\end{abstract}

Keywords: benefits transfer; China; dichotomous choice; environmental benefits valuation; health valuation; mortality valuation; payment card; risk valuation; stated preference; value of statistical life; anchoring; starting point bias.

*Corresponding author: Sandra Hoffmann, USDA Economic Research Service, Washington, DC, USA 20024 - 3221

Alan Krupnick: Resources for the Future, Washington, DC, USA 20036

Ping Qin: Department of Energy Economics, School of Economics, Renmin University of China, Beijing, China 
JEL classifications: H4; I15; I18; Q51; Q56; Q58.

\section{Introduction}

As this symposium demonstrates, there is increasing demand for monetary estimates of population health impacts in middle and lower income countries both for use in evaluating national programs and for making global comparisons (see also Bloom et al., 2012; Lomborg, 2013; World Bank IHME, 2016; Landrigan, 2017). There is particular interest in estimates of the value of reducing mortality risk (termed the value of statistical life or VSL), the most significant benefit from many population health and environmental programs (World Bank and IHME 2016 (air pollution); World Health Organization, 2015 (foodborne disease)). Yet, as a practical matter for most countries, analysts must use benefits estimates developed in other settings (see OECD, 2012). Such "benefits transfer" is most accurate when benefits comparisons are drawn from studies conducted in settings as similar as possible to those in which they are being applied (Johnston, Rolfe, Rosenberger \& Brouwer, 2015). A relatively large number of studies have been conducted in high income countries (OECD, 2012). Unfortunately, there is a paucity of primary VSL studies in low and middle income countries, which makes either finding appropriate country-specific VSL estimates or using benefits transfer from other low or middle income countries or from high income countries difficult. (See the papers in this symposium, including those by Robinson, by Hammitt, and by Viscusi and Masterman. See also Hammitt \& Robinson, 2011; Narain \& Sall, 2016; Landrigan, 2017.)

This article presents new VSL estimates for urban China and contributes to a set of studies explicitly designed to improve the capacity to transfer VSL values between countries. The goal of this study is two-fold: first, to enlarge the pool of high quality VSL studies in lower income countries; and second, to create a stronger empirical "bridge" between VSL estimates in high income countries and those in middle and low income countries as a means of strengthening the research foundation for VSL benefits transfer from higher to lower income countries. The common goal of the set of studies of which this study is a part is to use the same statedpreference survey instruments to estimate the VSL in multiple countries. While the survey instruments actually fielded vary slightly to accommodate differences in local conditions, effort was made in all studies to keep the core of the survey as similar as possible. These surveys have been fielded in cities in Mongolia (Hoffmann et al., 2012), China (World Bank, 2007), the U.K., France, and Italy (Alberini, Hunt \& Markandya, 2006b), Canada (Krupnick et al., 2002), Japan (Itaoka et al., 2007), and the United States (Alberini, Cropper, Krupnick \& Simon, 2004). This article presents results from a study using the instrument in additional Chinese cities. 
This paper also strengthens the ability of Chinese researchers and policy makers to transfer VSL estimates within China. The survey was administered to stratified random samples that are representative of the urban population in each of three Chinese cities: Shanghai, Nanning, and Jiujiang. These cities were identified by the Chinese government as broadly representative of large, medium, and small cities in China. In the 2010 Chinese census, the urban population in Chinese cities ranged from less than 500,000, to Shanghai with 23.0 million people in urban districts (Shanghai Statistics Bureau of Statistics, 23 September 2011); Nanning had 2.9 million people (as cited in "3-5主要年份各市按居住地分的城乡人口(2005-2014年)-数析网"), and Jiujiang had 705,000 (as cited in http://www.citypopulation.de/php/china-jiang xi-admin.php). The survey examines both contemporaneous and future risk reductions of a size typically achieved by air pollution policy. The study structure allows testing for internal and external scope sensitivity, for discounting, and for responsiveness of willingness to pay (WTP) to variations in income, age, and health status. We know of no other stated-preference study in China that has all of these features.

Finally, the study advances our understanding of stated-preference survey methodology by developing a novel approach to studying anchoring effects in payment-card stated-preference elicitation. Payment-card elicitation was initially developed to overcome excessive yea-saying, a form of starting point bias or anchoring, observed in stated-preference surveys. Yet, the visual design of payment cards may also elicit its own form of anchoring bias. This effect has not been well studied. Such study is important because payment-card elicitation has performed better than dichotomous choice elicitation in several developing countries.

We developed a computerized payment card that permits exploration of possible anchoring. In addition, because in a prior effort to field this survey in Chinese cities we used both a dichotomous choice (DC) and a computerized payment-card ("payment screen") (PC) elicitation format (World Bank, 2007), we can explore the hypothesis that estimates from DC and PC elicitation differ because of excessive yea-saying, or anchoring bias in the DC but not the PC elicitation format.

This paper is organized as follows. Section 2 presents a review of the literature on stated-preference VSL studies in China, studies comparing DC and PC elicitation formats, and the literature on anchoring in stated-preference studies. Section 3 describes the methodology used in this study. Section 4 discusses data preparation. Section 5 presents key WTP results and comparisons with other Chinese VSL studies. Section 6 presents results exploring the possibility of anchoring induced by the PC elicitation format. Section 7 compares our results with those from the other countries using the same basic survey instrument and discusses their implications for international benefits transfer. The paper ends with a summary of results and a brief discussion of conclusions. 


\section{Literature reviews}

\subsection{Stated-Preference Studies of VSL in China ${ }^{1}$}

There is a large and growing number of studies applying VSL estimates to measure policy impacts in China (Zhang, 2002; Aunan et al., 2004, 2007; Wang \& Mauzerall, 2006; Mead \& Brajer, 2008; Cao, Ho \& Jorgenson, 2009; Zhang et al., 2010; Yang, Teng \& Wang, 2013b; Aunan \& Wang, 2014; Wang et al., 2015; Lu, Yao, Fung \& Lin, 2016; Hua et al. 2013). Yet, there are only a handful of primary research studies estimating the VSL in China (Table 1$).^{2}$ One is a compensating wage differential study; the others use stated preference. These studies were conducted between 1995 and 2015. Our survey was fielded in 2006.

Past Chinese VSL studies vary widely in terms of both quality and quantitative estimates. Half of the eight studies in Table 1 either used convenience sampling or did not pass a scope test. Among the remaining studies, the VSL estimate from stated-preference surveys ranged from $\$ 150,619$ to $\$ 1.1$ million. Only one study clearly reported the size of the risk reduction. The high estimate is from a road fatality study. A recent meta-analysis finds that road fatalities have an ambiguous influence on VSL estimates, statistically higher VSL estimates in the meta-analysis's full sample models and not significant or lower VSL estimates when the sample is screened using the meta-analysis's authors preferred model (OECD, 2012). The one compensating wage study in Table 1 estimated a VSL of $\$ 65,587-\$ 152,990$, but noted that this estimate may be biased downward due to substantial unemployment compared with other compensating wage studies that can credibly assume full employment (Guo \& Hammitt, 2009).

None of the Chinese stated-preference studies, including ours, use a nationally representative sample. Because of the size and economic and cultural diversity of China, one might expect regional variation in the VSL. All prior studies, except for those by Guo and Hammitt (2009), Zhai (2011), and Wang and He (2014), were conducted in urban areas (Table 1). Our study broadens the basis for estimating the VSL in China. We provide comparable results for three cities, Shanghai, Nanning, and Jiujiang, which were selected by the Chinese government as being representative of large, medium, and small cities. We know of no prior VSL studies in Shanghai and Nanning.

1 In this review, we have not addressed issues with stated-preference studies in general, such as hypothetical bias. Johnston et al. (2017) provide a recent and comprehensive article on stated-preference best practices and issues.

2 We also found references to two additional studies (Li et al., 2002; Zeng \& Jiang, 2010), but could not obtain the studies. 
Table 1 Mean VSL for past mortality risk valuation studies in China.*

\begin{tabular}{|c|c|c|c|c|c|c|c|}
\hline Study & $\begin{array}{r}\text { Year survey } \\
\text { conducted }\end{array}$ & $\begin{array}{l}\text { Sample } \\
\text { type }\end{array}$ & $\begin{array}{l}\text { Risk type; } \\
\text { reduction size } \\
\# / 10,000 \text { popula- } \\
\text { tion }\end{array}$ & $\begin{array}{l}\text { Elicitation } \\
\text { format }\end{array}$ & Scope tests & VSL (\$US 2016) & $\begin{array}{l}\text { Survey } \\
\text { location }\end{array}$ \\
\hline Yang, Liu and Xu (2016) & 2014-2015 & Random & $\begin{array}{l}\text { Road fatality } \\
\text { (public good); na }\end{array}$ & $\begin{array}{l}\text { Double-bounded } \\
\text { dichotomous } \\
\text { choice }\end{array}$ & Passed $^{1}$ & $\$ 1,075,071$ & Nanjing \\
\hline Wang and He (2014) & 2000 & Random & $\begin{array}{l}\text { All cause cancer } \\
\text { morbidity and } \\
\text { mortality (private } \\
\text { good); } 100 \% \text { of } \\
\text { mean population } \\
\text { cancer rate for } 1 \\
\text { year }\end{array}$ & $\begin{array}{l}\text { Multi-bounded } \\
\text { dichotomous } \\
\text { choice }\end{array}$ & na & $\$ 246,859-\$ 417,761$ & $\begin{array}{l}\text { Rural Danyang, } \\
\text { Liupanshui, and } \\
\text { Tianjin }\end{array}$ \\
\hline Liu and Zhao (2013) & 2011 & Convenience & $\begin{array}{l}\text { Road fatality } \\
\text { (public good); } \\
0.1-0.15\end{array}$ & $\begin{array}{l}\text { Choice } \\
\text { experiment }\end{array}$ & Passed & $\$ 117,186$ & Dalian \\
\hline Zhai (2011) & 2006 & Random & $\begin{array}{l}\text { Fatality risk from } \\
\text { tsunamis (public } \\
\text { good); } 20\end{array}$ & Payment card & Not passed & $\$ 11,601$ & Coastal Tianjin \\
\hline $\begin{array}{l}\text { Ohdoko, Komatzu and } \\
\text { Kaneko (2013) }\end{array}$ & 2008 & Convenience & $\begin{array}{l}\text { Air pollution } \\
\text { related cancer } \\
\text { deaths } \\
\text { (public good); } \\
0-2.6\end{array}$ & $\begin{array}{l}\text { Choice } \\
\text { experiment }\end{array}$ & Passed & $\begin{array}{l}\$ 1,255,923 \\
\$ 1,672,901\end{array}$ & Jiujiang Changsha \\
\hline
\end{tabular}


Table 1 (Continued).

\begin{tabular}{|c|c|c|c|c|c|c|c|}
\hline Study & $\begin{array}{r}\text { Year survey } \\
\text { conducted }\end{array}$ & $\begin{array}{l}\text { Sample } \\
\text { type }\end{array}$ & $\begin{array}{l}\text { Risk type; } \\
\text { reduction size } \\
\# / 10,000 \text { popula- } \\
\text { tion }\end{array}$ & $\begin{array}{l}\text { Elicitation } \\
\text { format }\end{array}$ & Scope tests & VSL (\$US 2016) & $\begin{array}{l}\text { Survey } \\
\text { location }\end{array}$ \\
\hline Wang and Mullahy (2006) & 1998 & Random & $\begin{array}{l}\text { All air pollution } \\
\text { fatalities (public } \\
\text { good); } 0.5\end{array}$ & $\begin{array}{l}\text { Open-ended with } \\
\text { follow up }\end{array}$ & na & $\$ 150,619$ & Chongqing \\
\hline Hammitt and Zhou (2006) & 1999 & Random & $\begin{array}{l}\text { Generic } \\
\text { mortality, } \\
\text { in survey about } \\
\text { colds and bron- } \\
\text { chitis (private } \\
\text { good); } 10\end{array}$ & $\begin{array}{l}\text { Double-bounded } \\
\text { dichotomous } \\
\text { choice }\end{array}$ & Not passed & $\begin{array}{r}\$ 50,063-\$ 100,126 \\
\$ 333,753-\$ 600,756 \\
\$ 150,189-\$ 200,252\end{array}$ & $\begin{array}{l}\text { Anqing } \\
\text { Rural Anqing } \\
\text { Beijing }\end{array}$ \\
\hline Guo and Hammitt (2009) & 1995 data & Random** & $\begin{array}{l}\text { Occupational } \\
\text { fatality (private } \\
\text { good); } 0.61\end{array}$ & $\begin{array}{l}\text { Compensating } \\
\text { wage analysis }\end{array}$ & na & $\$ 62,587-\$ 152.990$ & Eleven provinces \\
\hline
\end{tabular}

*Sources: OECD (2017), Purchasing power parities (PPP) (indicator). doi: 10.1787/1290ee5a-en (accessed on April 4, 2017). U.S. Consumer Price Index, all consumers, 1913-, https://www.minneapolisfed.org/community/teaching-aids/cpi-calculator-information/consumer-price-index-and-inflation-rates-1913

(accessed on April 4, 2017). DC = dichotomous choice; na = not applicable or not provided. ** Registered urban residents only (have hukou), excludes migrants.

${ }^{1}$ Passing scope is defined as a decrease in risk being associated with a statistically significant increase in WTP for the risk reduction. 
Prior Chinese studies vary by the type of benefit provided. All prior studies except for that by Wang and He (2014) and the two studies co-authored by Hammitt valued reduction of risk of death as a public good (Table 1). All studies except for those by Hammitt and Zhou (2006) and Wang and He (2014) asked about deaths from specific hazards, including road fatalities, tsunamis, occupational hazards, and air pollution. Ohdoko et al. (2013) and Wang and He (2014) elicited WTP to reduce risk of death from cancer. There is a substantial literature studying whether WTP to reduce risk of death is higher for cancer than other causes of death, namely the “cancer premium" (Viscusi, Huber \& Bell, 2014). Our study elicited WTP for a private good that reduced risk of death. We did not specify the hazard creating the risk of death, and so the amount can be interpreted as the respondent's WTP to reduce a generic risk of their own individual death.

Current exposures or injuries can increase either contemporaneous or delayed risk of death. Among prior Chinese VSL studies, only Zhai (2011) estimated WTP for a delayed mortality risk reduction. Respondents were reminded, somewhat ambiguously, that "it may take 20 years to complete" construction of tsunami protection (Zhai, 2011). We ask respondents about their WTP during each of the next 10 years for reductions in their own risk of death over a decade of life starting at age 70. We also ask respondents about their WTP for contemporaneous reductions in their own risk of death. This clear delineation of the time when risk reduction occurs allows us to estimate a private discount rate for WTP for latent risk reductions.

The size of the risk reduction considered also varies among the studies. Prior Chinese VSL studies have looked at mortality risk reductions that range from $(1 / 100,000$ per year) to $(20 / 10,000$ per year) (Table 1$)$. Our study examines risk reductions of 5 and 10 in 10,000 per year; reduction levels that are typical of those that have been achieved by policies that significantly reduced particulate air pollution in other countries.

Validity tests are increasingly looked to as evidence of stated-preference study reliability. Five of the eight prior Chinese studies were designed to test for sensitivity to the size of the risk reduction; only three passed this scope test in the sense that the study found a statistically significantly larger WTP for samples given the larger risk reduction (Table 1). Our study provides three tests of scope: (1) a direct comparison of single individuals responses (internal scope); (2) direct comparison of responses across individuals (external scope); and (3) tests for the statistical significance of the regression coefficient on the size of the risk reduction. 


\subsection{Payment-card studies}

It has long been recognized that DC formats are subject to yea-saying bias, i.e., respondents tend to accept whatever bid is presented to them (Blamey, Bennett \& Morrison, 1999). Yea-saying may be due to social acquiescence or anchoring on salient or first presented information (Blamey et al., 1999; Mitchell \& Carson, 1989, 240-41). Mitchell and Carson (1981, 1984) developed the PC elicitation format as a means of addressing yea-saying bias observed in responses to open-ended and DC elicitation formats in stated-preference surveys.

Yea-saying or starting point bias has been offered as a reason why WTP estimated from DC surveys is typically higher than that estimated with PC formats (Champ \& Bishop, 2006). In developed countries, WTP based on DC surveys generally has been found to be 2-4 times higher than that estimated using PC surveys (Holmes \& Randall, 1995; Brown, Champ, Bishop \& McCollum, 1996; Ready, Buzby \& Hu, 1996; Welsh \& Poe, 1998; Ready, Navrud \& Richard Dubourg, 2001; Ryan, Scott \& Donaldson, 2004; Blaine, Lichtkopper, Jones \& Zondag, 2005; Champ \& Bishop, 2006; Myers, Parsons \& Edwards, 2010).

Payment-card elicitation presents respondents with a list or matrix of values and asks respondents to pick the value that most closely approximates their maximum willingness to pay for the good in question. The visual format of a payment card itself may inadvertently create anchoring points. This is most obvious with a list, but may also occur with a matrix. While the presence of starting point bias in DC stated-preference elicitation has been widely documented, there is far less research on whether or how it might occur with PC elicitation (Smith, 2006; Yang, Qing, Hu \& Liu, 2013a). Smith (2006) compared three PC formats, a list ordered high to low, a list ordered low to high, and randomly sorted bid cards. It was found that WTP was higher for the high to low list than for the other two PC formats, suggesting that for lists, respondents may anchor on the first value seen when it is the highest value, but not when it is the lowest. Yang et al. $(2013 a, b)$ found evidence of starting point bias in PC elicitation about consumers' WTP for fair trade coffee in Wuhan, China, but did not describe the format of the PCs used. We develop a new approach to testing for starting point bias in a PC matrix that exploits the functionality of a computer screen. We intentionally create an anchor point in a computerized PC by randomly assigning the initial placement of a flashing cursor in a matrix of possible values and rigorously measuring the direction and distance the respondent moves away from that anchor to their final chosen value in the matrix.

There is an open question in the economics literature about the relative reliability of DC and PC elicitation formats in developing country settings. In industrialized countries, DC is widely used, in part due to a 1993 NOAA panel endorsement 
(Arrow et al., 1993). Several researchers have suggested that yea-saying may be a greater problem for DC elicitation in developing countries because respondents more frequently lack experience with elections, may be more unaccustomed to being asked for their opinion on provision of public goods, may be more apt to fear those in authority, or may have a stronger culture of acquiescence (Zhongmin, Loomis, Zhigiang \& Hamamura, 2006; Brown \& Huff, 2011). It is also possible that PC elicitation may be more comfortable for respondents who typically bargain over price, more common in developing countries, rather than make purchases in fixed-price markets that are more common in high income countries.

There are a small, but growing, number of studies comparing performance of DC and PC elicitation formats in low and middle income countries (Zhongmin et al., 2006; Heinzen \& Bridges, 2008; Jun-Peng \& Yong, 2008; Zhang \& Cai, 2010; Zhao et al., 2013). Most found that DC surveys produce higher WTP estimates than PC elicitation, but the studies provided only limited insight into why this may be occurring. In an earlier version of our China study, we administered a DC and PC version of the survey described this paper in Shanghai and Chongqing (World Bank, 2007). We found that a much higher percentage of respondents accepted all offers (yea-saying) in the DC version of the survey (21\% of the sample in Shanghai) than chose the same bid in the PC version (10\% of the Shanghai sample). Estimated WTP was 1.15-1.85 times as high in the DC as in the PC version of the survey. Finally, results from the DC version of the survey did not pass scope tests, in the sense of statistically significant increases in WTP with a decrease in risk, while those from the PC version did. Based on the literature described above and our own experience with using the DC survey in China (World Bank, 2007), we repeated the study using a PC approach. These new results are presented below.

\section{Survey development}

The survey instrument used in this study is in all ways except for the payment vehicle fundamentally the same as the survey we fielded in Shanghai and Chongqing, and fundamentally the same as those estimating WTP to reduce mortality risk in seven other countries (Krupnick et al., 2002; Alberini et al., 2004, 2006b; Itaoka et al., 2007; Hoffmann et al., 2012). The survey instrument used in these studies was translated into Chinese and adapted to reflect important demographic, cultural, and institutional conditions in China. In other respects, the survey was kept as close as possible to that administered elsewhere. In particular, it retains the same risk communication, risk comprehension testing, and the same elicitation design 
that allows internal and external scope tests, and other robustness/validity testing described more fully in Hoffmann et al. (2012).

Focus group results led us to a change in the risk reduction vehicle used in the survey. In prior versions of the survey in high income countries, respondents were told that a "product" existed that they could purchase to reduce mortality risk by specified amounts. These surveys produced credible results. However, Chinese focus group participants did not find this product credible. In debriefings, they said that it brought to mind several recent, well-publicized cases in China of health products offered under fraudulent claims of efficacy. Working with focus groups, we developed an alternative that permits respondents to choose their method for reducing risk from among three options: a medical treatment, a prevention measure, and "other" measures. Focus group participants found this approach to be credible.

Focus group results suggested that the survey instrument used in high income countries could be successfully conducted in urban China with few other modifications. A concern prior to pretests was whether respondents, particularly older respondents, would be comfortable with using a computer to take the survey. Pretests showed that within five minutes or less, after initial assistance and brief training, ordinary Chinese respondents, even older respondents, were able to be self-sufficient in taking the computer-administered survey. Focus group results suggested that mortality risk reductions of 5 in 10,000 and 10 in 10,000 per year could be used in the study.

\subsection{Survey questionnaire}

All respondents were asked about their WTP for a 5 in 1000 and 10 in 1000 contemporaneous risk reduction over the next 10 years (Table 2). Half of the respondents (wave 1) were asked first about their willingness to pay for a 5 in 1000 risk reduction; the other half (wave 2) were asked first about their willingness to pay for a 10 in 1000 risk reduction. In both cases, for people under 61, the contemporaneous risk reduction question was followed by two delayed risk reduction questions. For people aged 61-65, the first question was followed by another contemporaneous risk reduction question followed by one with a delayed risk reduction (for people aged 61-65). Respondents over 65 were only given two contemporaneous risk reduction questions.

The contemporaneous risk reduction questions ask about a respondent's WTP for their choice of product or action that, when used and paid for over the next 10 years, will reduce baseline risk by $x$ in 1000 over the 10-year period (Figure 1(a)). The delayed risk reduction questions ask about their willingness to pay for their 
Table 2 Study design.

\begin{tabular}{|c|c|c|c|c|c|}
\hline \multirow[t]{3}{*}{$\begin{array}{l}\text { Group of } \\
\text { respondents }\end{array}$} & \multirow[t]{3}{*}{$\begin{array}{r}\text { Initial current risk } \\
\text { reduction valued }\end{array}$} & \multicolumn{2}{|c|}{$\begin{array}{c}\text { Second risk reduction } \\
\text { valued }\end{array}$} & \multirow{2}{*}{\multicolumn{2}{|c|}{$\begin{array}{c}\begin{array}{c}\text { Third risk reduction } \\
\text { valued }\end{array} \\
\text { Future risk reduction }\end{array}$}} \\
\hline & & Future risk & Current risk & & \\
\hline & & Age 40-60 & $61+$ & Age 40-60 & Age 61-65 \\
\hline Wave 1 & & 5 in 1000 & 10 in 1000 & 5 in 1000 & 10 in 1000 \\
\hline Wave 2 & & 10 in 1000 & 5 in 1000 & 10 in 1000 & 5 in 1000 \\
\hline
\end{tabular}

Note: Respondents over 65 did not get a future risk reduction question.

choice of product or action that, when used and paid for over the next 10 years, will reduce their baseline risk by $x$ in 1000 , for a 10 -year period beginning at age 70 (Figure 1(b)). The delayed risk reduction questions are preceded by a question concerning the respondent's perceived chance of surviving to age 80 . This question encourages the respondent to think about their future life expectancy.

The survey design permits both internal and external scope tests. These tests involve comparing WTP responses across questions, either for an individual (the internal scope test) or between individuals (the external scope test).

\subsection{Elicitation format}

The elicitation uses a computerized version of a PC that we call a payment screen. All respondents see that same matrix of bids (Figure 1(a)). Respondents are asked to choose the bid most closely reflecting their maximum WTP. Possible bids range from 0 to 2500 yuan per year for 10 years. This covers the range of WTP found in other countries, converted to yuan using a purchasing power parity (PPP) exchange rate. Rowe, Schulze and Breffle (1996) found that PC elicitation did not show sensitivity to range as long as the range of respondents' desired bids was covered. Pretests found no indication that the 0-2500 yuan range was constraining respondents' choices. Intervals were designed to be roughly constant in percentage terms. Psychometric studies and experimental economics suggest this approach as a means of reducing response error (Rowe et al., 1996; Ready et al., 2001).

Computer administration of the survey allowed us to randomly assign an initial cursor placement within the matrix of possible bids to each individual respondent. For a given individual respondent, this initial cursor placement was kept the same for all WTP questions. If there were starting point bias, using the same starting point 
(a)

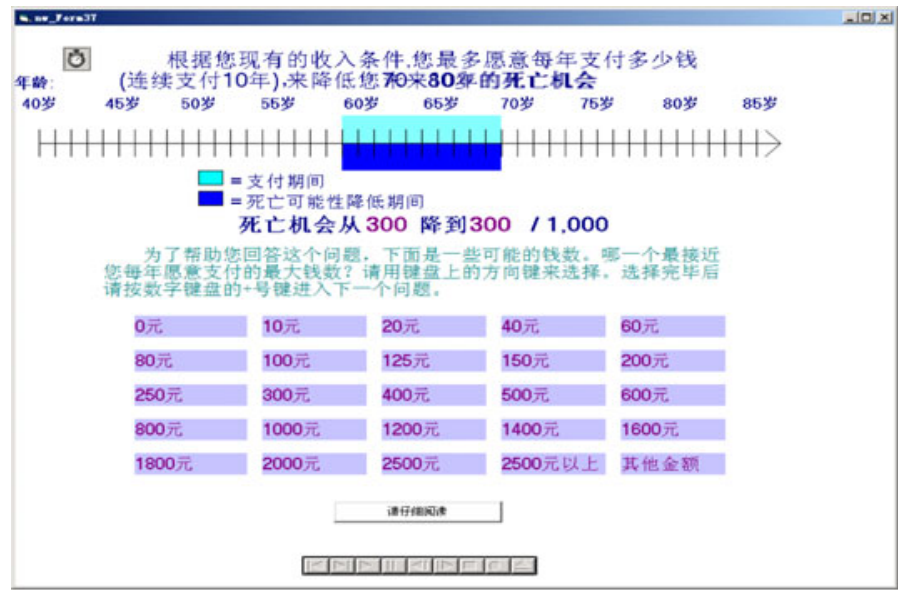

(b)
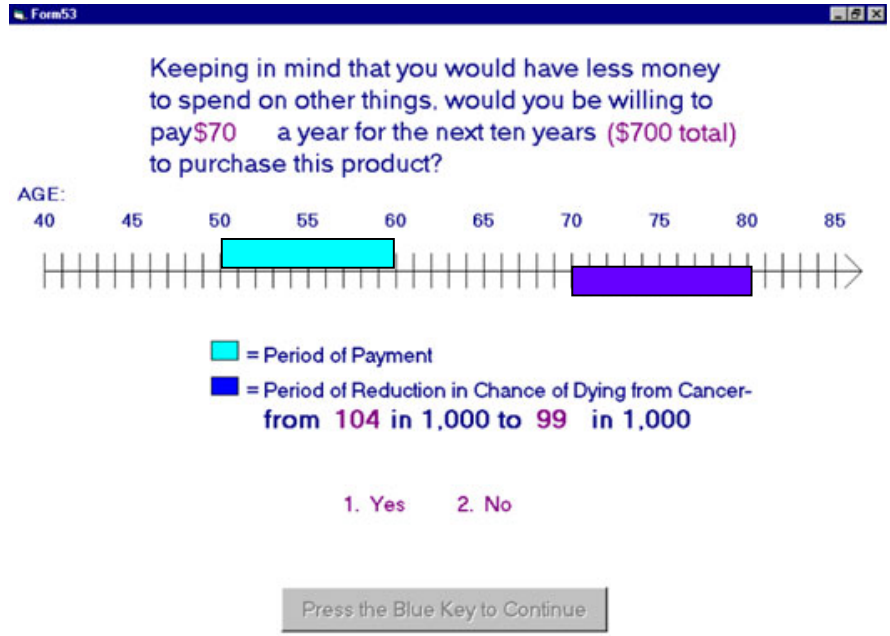

Figure 1 (a) The payment screen elicitation format. Current risk reduction. (b) Delayed risk reduction (in dichotomous choice format).

for each question for a given individual would work against finding sensitivity to scope, strengthening the internal scope test.

Use of a computerized payment screen rather than a paper PC allows us to track movement of the cursor between initial placement and final choice. This allows us to test for influence of the starting point on WTP. Coupled with debriefing questions and screening criteria, it also allows us to test the hypothesis that respondents who 
click on a number further from the starting cursor position produce more consistent answers (are more engaged in the survey process) than those who click at or closer to the starting position. Finally, the randomized starting point and computerized tracking of cursor movements allow us to test for whether there is any bias in the direction of cursor movement, either numerically or visually.

\subsection{Estimation model}

The theoretical framework for this study is a life-cycle model of consumption linking WTP for mortality risk reduction and the VSL (Cropper \& Sussman, 1990). This framework is described in depth in Alberini, Cropper, Krupnick and Simon (2006a).

We use estimation methods that are as similar as possible to those used in prior versions of the survey (Alberini et al., 2004; Hoffmann et al., 2012). Because we are using a PC format, the chosen WTP can be thought of in one of three ways. One, we estimate WTP as a direct estimate of the respondent's actual WTP (stated WTP). Two, we estimate WTP as the top end of an interval between the chosen number and the next lowest number (which we estimated using a Weibull and lognormal distribution, though we report only the former due to space concerns). Three, to be yet more conservative, we also set WTP at the value in the matrix immediately below the chosen number (which is similar to the lower Turnbull estimate in the DC version of the survey). In order of conservativeness of the WTP estimate, (3) is most conservative and (1) is least conservative.

\subsection{Survey administration}

The same stratified random sampling protocol was used in all study cities. Shanghai provides an example of this protocol. At the time of this survey, Shanghai had a population of $17,110,000$. The city was divided into 18 urban districts which were subdivided into 100 communities (street offices in Chinese). These, in turn, were further subdivided into 3241 neighborhoods. Three urban districts (Pu Dong, Hong Kou, and Yang Pu districts), four communities within each district, and four neighborhoods per community were chosen at random. Within each neighborhood, households were randomly drawn from a "population information network" set up by the Shanghai Government to provide reproductive services to married couples. An adult aged 40 or over was chosen randomly from within the household. As most Shanghai residents over age 40 are married or living with younger married family members, this network provided us with sufficient information for sampling. 
We recognize that people who never married, older people who do not live with their children (3\%-4\% of older people (State Statistical Bureau of the People's Republic of China, 2006)), and recent migrants were not included in the sampling frame. Chinese researchers advised that the population information network was the best available database for sampling in the studied cities and is widely used as a sampling frame in population surveys. Education, gender, and age structure were considered when sampling. The protocol oversampled older adults, calling for onethird of the sample to be 61 or over model to examine the relationship between age and WTP for reductions in mortality risk.

The survey was administrated on the weekends to accommodate working people. Neighborhood-center staff contacted respondents, inviting them to take the survey on the following weekend. Those who agreed came to the neighborhood center, where a Fudan University graduate student administered the survey. Participants were given a gift valued at 20 yuan for their participation. The survey was administered in 2006; 980 respondents completed the survey in Shanghai, 337 in Nanning, and 344 in Jiujiang. Response rates were about 64\% in Shanghai, and higher in the other cities. Given the approach of obtaining interviews, such rates are not comparable to those of other more standard approaches used in the West.

\section{Screening on response quality}

We employed a number of methods recommended to address concerns about consequentiality and potential hypothetical bias (Kling, Phaneuf \& Zhao, 2012). These included reminding respondents of their incomes and household expenditure needs, using focus groups to create as credible and consequential a choice setting as possible, and using follow-up questions and tests of understanding of probability to identify respondents who did not understand the survey or take it seriously (Table 3). Characteristics flagged included those who failed tests on understanding of probability (FLAG1), chose the initial cursor position for all choices (NOMOVE), always gave the same bid (SAMEBID), and those who said they did not understand probability, but still passed the probability tests (FLAG6). We also identified those who always bid zero (BAD ZERO) or always bid the highest possible amount (BAD 2500) and answered debriefing questions in a way suggesting that they did not believe the survey or had other problems with the survey. Finally, because life expectancy of Chinese urban dwellers at 65 is 84 for males and 87 for females (Li, 2015), people over 80 years of age are not expected to experience many of the benefits offered and were therefore dropped from the sample (OVER80). Table 3 reports descriptive statistics on these screening criteria. 
Table 3 Descriptive statistics for full sample.

\begin{tabular}{|c|c|c|c|c|c|c|c|c|}
\hline & \multicolumn{2}{|c|}{ Pooled $(n=1081)$} & \multicolumn{2}{|c|}{ Shanghai $(n=380)$} & \multicolumn{2}{|c|}{ Nanning $(n=357)$} & \multicolumn{2}{|c|}{ Jiujiang $(n=344)$} \\
\hline & Mean & SD & Mean & SD & Mean & SD & Mean & SD \\
\hline Age & 54.47 & 10.29 & 55.43 & 10.22 & 54.55 & 10.28 & 53.32 & 10.31 \\
\hline Household income (yuan) & 49,500 & 35,821 & 77,550 & 39,251 & 34,811 & 25,073 & 33,760 & 18,460 \\
\hline \multirow[t]{2}{*}{ Household size } & 3.69 & 1.45 & 3.17 & 1.36 & 3.94 & 1.44 & 4.01 & 1.39 \\
\hline & \multicolumn{8}{|c|}{ Per cent } \\
\hline Male & 51.25 & & 49.21 & & 50.98 & & 53.78 & \\
\hline Married & 89 & & 86.3 & & 90.2 & & 90.7 & \\
\hline Have some college education & 11.1 & & 22.37 & & 5.6 & & 4.46 & \\
\hline Buy commercial insurance & 26.3 & & 10 & & 35.9 & & 34.3 & \\
\hline Have had cancer & 1.67 & & 2.11 & & 0.56 & & 2.03 & \\
\hline Have high blood pressure & 27.66 & & 38.16 & & 17.09 & & 22.38 & \\
\hline Have had a coronary attack & 5.99 & & 10.5 & & 3.6 & & 3.5 & \\
\hline Have had a stroke & 2.03 & & 4.2 & & 1.4 & & 0.3 & \\
\hline Have had other types of heart disease & 7.20 & & 10.5 & & 3.6 & & 7.3 & \\
\hline Have diabetes & 5.53 & & 8.9 & & 1.1 & & 6.4 & \\
\hline Have chronic bronchitis & 11.36 & & 7.63 & & 9.24 & & 15.90 & \\
\hline Have asthma & 4.26 & & 3.7 & & 2.8 & & 6.4 & \\
\hline Have chronic obstructed pulmonary disease (COPD) & 0.91 & & 0.5 & & 0.6 & & 1.7 & \\
\hline
\end{tabular}


Table 3 (Continued).

\begin{tabular}{|c|c|c|c|c|c|c|c|c|}
\hline & \multicolumn{2}{|c|}{ Pooled $(n=1081)$} & \multicolumn{2}{|c|}{ Shanghai $(n=380)$} & \multicolumn{2}{|c|}{ Nanning $(n=357)$} & \multicolumn{2}{|c|}{ Jiujiang $(n=344)$} \\
\hline & Mean & SD & Mean & SD & $\overline{\text { Mean }}$ & SD & Mean & $\overline{\text { SD }}$ \\
\hline Have visited an emergency room & 8.12 & & 8.4 & & 3.6 & & 12.5 & \\
\hline Have stayed in a hospital & 2.56 & & 3.9 & & 0.8 & & 2.9 & \\
\hline Expect to have worse health in 10 years & 79.75 & & 76.6 & & 76.5 & & 86.6 & \\
\hline Expect to have better health at 75 & 1.11 & & 1.58 & & 0.84 & & 0.87 & \\
\hline Expect to live to age 80 & 45.08 & & 65.3 & & 45.4 & & 22.4 & \\
\hline Failed probability test (FLAG1) & 0.19 & & 0.26 & & 0 & & 0.29 & \\
\hline Chose initial bid placement (NOMOVE) & 9.63 & & 7.37 & & 8.96 & & 12.50 & \\
\hline Always chose same bid (SAMEBID) & 9.07 & & 10.0 & & 11.48 & & 5.52 & \\
\hline Always chose zero + bad debriefing (BAD ZERO) & 2.13 & & 3.68 & & 1.96 & & 0.58 & \\
\hline Always chose $2500+$ bad debriefing (BAD 2500) & 0.18 & & 0.0 & & 0.56 & & 0.0 & \\
\hline Said did not understand probability (FLAG6) & 19.52 & & 7.37 & & 33.89 & & 18.02 & \\
\hline Over age 80 (OVER80) & 1.67 & & 2.11 & & 2.24 & & 0.58 & \\
\hline
\end{tabular}


Two screening approaches proved to be useful in explaining WTP. The first, screening approach A, dropped only those over 80 and those who failed the probability test. The second, screening approach $\mathrm{B}$, additionally dropped those who failed any of the screening criteria discussed above (Table 3). Follow-up questions indicating that respondents were not taking the survey seriously were explored, but not found to explain WTP. In the pooled data across all cities, screening approach A dropped $2.3 \%$ of the sample; screening approach B dropped $34.3 \%$ (Tables 3 and 4).

\section{Willingness to pay results}

\subsection{Descriptive statistics}

Table 3 reports descriptive statistics in aggregate and across cities. Differences in income, education, and, to some extent, health are seen across the cities included in the study. The respondents from Jiujiang were slightly younger than those from Shanghai or Nanning (mean age of 53 compared with 55). This difference is statistically significant. A higher percentage of respondents in Shanghai had some college education (22.4\%) compared with respondents in Jiujiang (4.5\%) or Nanning (5.6\%). The difference between Jiujiang and Nanning is not statistically significant. Mean household income in Shanghai was also significantly higher than that in the other cities - 77,550 RMB compared with Nanning (34,811 RMB) and Jiujiang $(33,760 \mathrm{RMB})$. Income differences between Nanning and Jiujiang are not statistically significant.

Experience with health and health care is expected to affect WTP to reduce mortality risk, based on results in other countries. Differences between the percentage of respondents who believe they will live to age 80 in each of the three cities are statistically significant, $22.4 \%$ in Jiujiang, $45.4 \%$ in Nanning, and 65.3\% in Shanghai. A higher percentage of respondents in Shanghai had some sort of heart disease than in Nanning and Jiujiang, and a higher percentage of respondents in Jiujiang reported having had asthma or bronchitis than respondents in the other cities. Fewer respondents in Nanning had had cancer than in Shanghai or Jiujiang. Respondents in Nanning were less likely to have visited an emergency room or stayed in a hospital than respondents in the other cities. A higher percentage of respondents in Jiujiang expected their health to be worse in 10 years (87\%), even though they were slightly younger than respondents in Nanning or Shanghai (both about 77\%). This difference is statistically significant. Various specifications of health status or experience were tried below in regressions explaining WTP. 
Table 4 Willingness to pay (in yuan) under alternative data screening approaches. ${ }^{\text {a }}$

\begin{tabular}{|c|c|c|c|c|c|c|c|c|c|c|c|c|c|c|c|c|}
\hline \multirow{3}{*}{ Screening Approach } & \multicolumn{4}{|c|}{ Shanghai } & \multicolumn{4}{|c|}{ Nanning } & \multicolumn{4}{|c|}{ Jiujiang } & \multicolumn{4}{|c|}{ Pooled } \\
\hline & \multicolumn{2}{|c|}{$\mathbf{A}$} & \multicolumn{2}{|c|}{ B } & \multicolumn{2}{|c|}{$\mathbf{A}$} & \multicolumn{2}{|c|}{ B } & \multicolumn{2}{|c|}{$\mathbf{A}$} & \multicolumn{2}{|c|}{ B } & \multicolumn{2}{|c|}{$\mathbf{A}$} & \multicolumn{2}{|r|}{ B } \\
\hline & $\mathbf{N}$ & Mean & $\mathbf{N}$ & Mean & $\mathbf{N}$ & Mean & $\mathbf{N}$ & Mean & $\mathbf{N}$ & Mean & $\mathbf{N}$ & Mean & $\mathbf{N}$ & Mean & $\mathbf{N}$ & Mean \\
\hline \multicolumn{17}{|l|}{ Lower Turnbull } \\
\hline WTP5 $^{\circ}$ & 177 & 560 & 143 & 614 & 166 & 667 & 43 & 1037 & 153 & 657 & 73 & 868 & 496 & 626 & 333 & 663 \\
\hline WTP $10^{\circ}$ & 193 & 784 & 150 & 838 & 179 & 782 & 55 & 1159 & 188 & 865 & 89 & 1167 & 560 & 811 & 377 & 877 \\
\hline WTP5_70 & 145 & 520 & 111 & 565 & 138 & 468 & 47 & 738 & 126 & 400 & 59 & 588 & 409 & 466 & 284 & 506 \\
\hline WTP10_70 & 118 & 732 & 92 & 824 & 122 & 631 & 39 & 1185 & 127 & 755 & 70 & 1080 & 367 & 706 & 248 & 827 \\
\hline Scope tests & t-statistic & $\mathrm{p}$ & t-statistic & $\mathrm{p}$ & t-statistic & $\mathrm{p}$ & t-statistic & $\mathrm{p}$ & t-statistic & $\mathrm{p}$ & t-statistic & $\mathrm{p}$ & t-statistic & $\mathrm{p}$ & t-statistic & $\mathrm{p}$ \\
\hline 5 versus 10 & $3.90^{*}$ & 0.00 & $3.48^{*}$ & 0.00 & $1.68^{*}$ & 0.05 & 0.79 & 0.22 & $3.53^{*}$ & 0.00 & $3.36^{*}$ & 0.00 & $5.19^{*}$ & 0.00 & $5.01^{*}$ & 0.00 \\
\hline $5 \_70$ versus $10 \_70$ & $3.00^{*}$ & 0.00 & $3.13^{*}$ & 0.00 & $2.33^{*}$ & 0.01 & $2.86^{*}$ & 0.09 & $5.7^{*}$ & 0.00 & $4.81^{*}$ & 0.00 & $6.15^{*}$ & 0.00 & $6.64^{*}$ & 0.00 \\
\hline \multicolumn{17}{|l|}{ Discount test } \\
\hline 5 versus $5 \_70$ & 0.75 & 0.23 & 0.77 & 0.22 & $2.93^{*}$ & 0.00 & $1.95^{*}$ & 0.03 & $4.57^{*}$ & 0.00 & $32.89^{*}$ & 0.00 & $4.64^{*}$ & 0.00 & $3.77^{*}$ & 0.00 \\
\hline 10 versus $10 \_70$ & 0.71 & 0.24 & 0.17 & 0.43 & $2.09^{*}$ & 0.02 & 0.16 & 0.56 & $1.68^{*}$ & 0.05 & 0.92 & 0.18 & $2.57^{*}$ & 0.01 & 0.10 & 0.16 \\
\hline \multicolumn{17}{|l|}{ Weibull } \\
\hline WTP5 $^{\circ}$ & 168 & 606 & 142 & 687 & 161 & 753 & 43 & 1043 & 152 & 726 & 73 & 874 & 481 & 710 & 331 & 736 \\
\hline WTP $10^{\circ}$ & 186 & 888 & 150 & 912 & 167 & 915 & 55 & 1166 & 187 & 943 & 89 & 1164 & 540 & 915 & 377 & 954 \\
\hline WTP5_70 & 139 & 606 & 111 & 633 & 129 & 551 & 45 & 774 & 123 & 458 & 59 & 593 & 391 & 541 & 282 & 565 \\
\hline WTP10_70 & 109 & 864 & 90 & 918 & 112 & 763 & 38 & 1218 & 127 & 823 & 70 & 1077 & 348 & 817 & 244 & 923 \\
\hline
\end{tabular}


Table 4 (Continued).

\begin{tabular}{|c|c|c|c|c|c|c|c|c|c|c|c|c|c|c|c|c|}
\hline \multirow{3}{*}{ Screening Approach } & \multicolumn{4}{|c|}{ Shanghai } & \multicolumn{4}{|c|}{ Nanning } & \multicolumn{4}{|c|}{ Jiujiang } & \multicolumn{4}{|c|}{ Pooled } \\
\hline & \multicolumn{2}{|c|}{$\bar{A}$} & \multicolumn{2}{|c|}{ B } & \multicolumn{2}{|c|}{$\mathbf{A}$} & \multicolumn{2}{|c|}{ B } & \multicolumn{2}{|c|}{$\mathbf{A}$} & \multicolumn{2}{|c|}{ B } & \multicolumn{2}{|c|}{$\mathbf{A}$} & \multicolumn{2}{|c|}{ B } \\
\hline & $\mathbf{N}$ & Mean & $\mathbf{N}$ & Mean & $\mathbf{N}$ & Mean & $\mathbf{N}$ & Mean & $\mathbf{N}$ & Mean & $\mathbf{N}$ & Mean & $\mathbf{N}$ & Mean & $\mathbf{N}$ & Mean \\
\hline Scope tests & t-statistic & $\mathrm{p}$ & t-statistic & $\mathrm{p}$ & t-statistic & $\mathrm{p}$ & t-statistic & $\mathrm{p}$ & t-statistic & $\mathrm{p}$ & t-statistic & $\mathrm{p}$ & t-statistic & $\mathrm{p}$ & t-statistic & $\mathrm{p}$ \\
\hline 5 versus $10 b$ & $62.50^{*}$ & 0.00 & $41.02^{*}$ & 0.00 & $2.62^{*}$ & 0.01 & $2.54^{*}$ & 0.01 & $4.85^{*}$ & 0.00 & $5.56^{*}$ & 0.00 & $128.5^{*}$ & 0.00 & $95.79 *$ & 0.00 \\
\hline 5_70 versus $10 \_70$ & $33.91^{*}$ & 0.00 & $30.15^{*}$ & 0.00 & $3.13^{*}$ & 0.00 & $3.96^{*}$ & 0.00 & $6.69^{*}$ & 0.00 & $7.38^{*}$ & 0.00 & $123.4^{*}$ & 0.00 & $111.69^{*}$ & 0.00 \\
\hline \multicolumn{17}{|l|}{ Discount test } \\
\hline 5 versus $5 \_70$ & 0.00 & 0.5 & $8.91^{*}$ & 0.00 & $6.17^{*}$ & 0.00 & $5.86^{*}$ & 0.00 & $6.89^{*}$ & 0.00 & $6.31^{*}$ & 0.00 & $102.18^{*}$ & 0.00 & $72.69^{*}$ & 0.00 \\
\hline 10 versus $10 \_70$ & $3.24^{*}$ & 0.00 & 0.66 & 0.26 & $5.76^{*}$ & 0.00 & $4.46^{*}$ & 0.00 & $5.17^{*}$ & 0.00 & $4.32^{*}$ & 0.00 & $44.69^{*}$ & 0.00 & $9.84^{*}$ & 0.00 \\
\hline
\end{tabular}

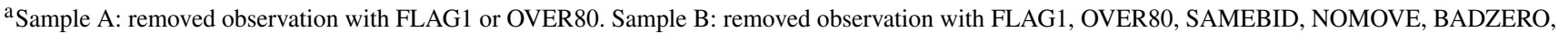

BAD2500, or FLAG6. WTPx is willingness to pay in yuan for an $x$ in 1000 reduction of mortality risk over the next 10 years, or an $x$ in 10,000 risk reduction annually. WTPx_70 is willingness to pay in yuan for an $x$ in 1000 reduction of mortality risk over 10 years beginning at age 70, or an $x$ in 10,000 risk reduction annually beginning at age 70 .

The estimates for contemporaneous WTP are based on the first WTP question. The delayed WTP is based on the second and third WTP questions. There is not much difference between using only the second WTP question and using both the second and third WTP questions.

${ }^{\circ}$ First question.

*Significant at the $10 \%$ level based on a 1 -tailed t-test. 


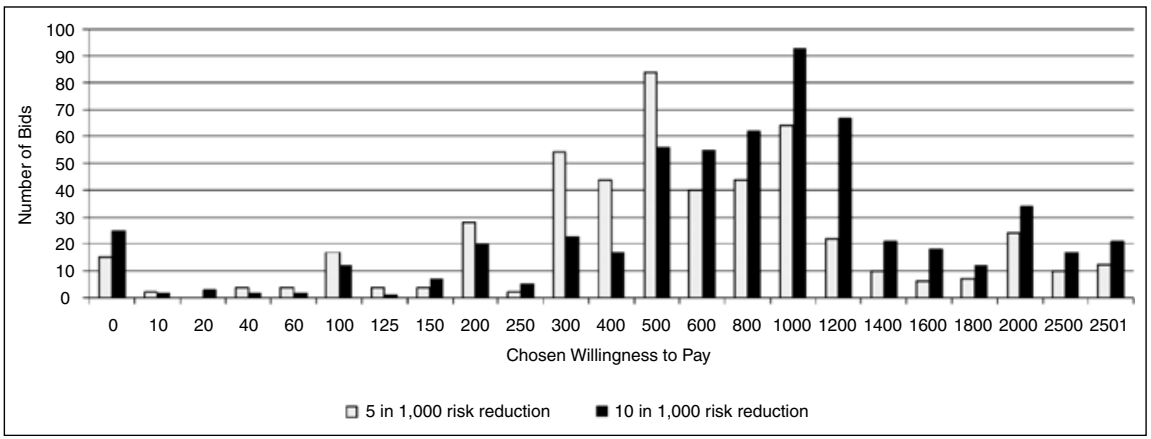

Figure 2 Frequency of current WTP by risk reduction (first question) for PC survey in Shanghai, Nanning, and Jiujiang (full sample).

\subsection{Willingness to pay raw responses}

Figure 2 shows the frequency distribution of raw responses (full sample over three cities) to the first WTP question by both waves, i.e., respondents who received either the 5 in 1000 or 10 in 1000 risk reduction question first. Low WTP values were chosen more frequently by those seeing the 5 in 1000 question first. From WTP of 600 and above, the relative number of those choosing a WTP category is higher for the group seeing the 10 in 1000 risk reduction question first. The figure also shows a tendency of responses to clump at the round numbers, i.e., 100, 1000, and 2000 yuan, a phenomenon that has been observed in past PC studies. The distributions for the screened samples (A and B) are quite similar to that shown in Figure 2 for the full sample, although the distribution for the 10 in 1000 first question is skewed toward the higher numbers relative to the curve for the 5 in 1000 distribution, and no respondents bid zero for the 10 in 1000 question.

\subsection{Contemporaneous WTP estimates and external scope tests}

Table 4 reports the WTP results for each city based on the two screening approaches. It should be noted that in screening approach B, we drop from $28 \%$ to $38 \%$ of the observations retained by screening approach A. The table contains WTP estimates for both contemporaneous and delayed risk reduction, and Wald test statistics for differences among these estimates. The WTP estimates were generated using lower 
Turnbull, Weibull, and stated value models, but only the first two are given in the table.

The WTP associated with a contemporaneous 5 in 1000 risk reduction over 10 years (or 5 in 10,000 per year) varies across cities, estimation models, and screening approaches. By construction, the lowest values are for the lower Turnbull model and the highest for the stated value model (not shown), with the Weibull model falling in the middle. Even though Shanghai has higher income than the other two cities, it tends to have the lowest WTP values across the cities, a statistically significant difference. Screening approach B always produces larger values than screening approach A, but not all of these differences are significant. The Weibull model provides the most consistent results across the two screening approaches. External scope tests were passed for all contemporaneous risk models, except screening approach B in Nanning (Table 4). Pooling all observations, the average lower Turnbull WTP estimate for a 5 in 10,000 annual mortality risk reduction is 663 yuan, or a VSL of 1.33 million yuan.

Were these results used to estimate WTP for mortality risk reduction in urban China, we would recommend binning Chinese cities into cities that socio-economically match one of the three cities in this study and applying the lower Turnbull estimator and screening approach B. For comparison with other countries, we find the Weibull model results to be more consistent with those from past studies. With screening B, the Weibull estimate of WTP for a 5 in 10,000 annual morality risk reduction is 736 yuan $(\mathrm{VSL}=1.47$ million yuan).

\subsection{Regression analysis on contemporaneous WTP}

Table 5 presents results of pooled regressions examining the construct validity of the payment screen survey responses to the first WTP question using a Weibull model. We report two model specifications. Model 1 examines the effect of age, education, and income on the WTP response as well as testing for scope effects. Model 2 adds health and other covariates.

For both A and B screening samples, income and the 5 in 1000 risk reduction are both significant and of the expected sign. The negative and highly significant coefficient on the 5 in 1000 risk reduction variable indicates that responses pass external scope even after controlling for other factors. Per capita income is measured as reported household income divided by the corresponding household size. The coefficient on per capita income in log form varies from 0.07 to 0.22 , which suggests an income elasticity of around 0.1 when the two risk change scenarios are 
Table 5 Construct validity of WTP for the current risk reduction. Pooled data from Shanghai, Nanning, and Jiujiang; Weibull distribution; first question.

\begin{tabular}{|c|c|c|c|c|}
\hline \multirow[b]{2}{*}{ Variable } & \multicolumn{2}{|c|}{ A sample } & \multicolumn{2}{|c|}{ B sample } \\
\hline & Model 1 & Model 2 & Model 1 & Model 2 \\
\hline Intercept & $\begin{array}{r}6.16^{* * *} \\
(0.05)\end{array}$ & $\begin{array}{r}6.33^{* * * *} \\
(0.37)\end{array}$ & $\begin{array}{r}5.46^{* * *} \\
(0.41)\end{array}$ & $\begin{array}{r}4.47^{* * * *} \\
(0.68)\end{array}$ \\
\hline Age $51-60$ & $\begin{array}{r}-0.17^{* * *} \\
0.05\end{array}$ & $\begin{array}{r}-0.11^{* *} \\
(0.05)\end{array}$ & $\begin{array}{r}-0.23^{* * *} \\
(0.06)\end{array}$ & $\begin{array}{r}-0.17^{* *} \\
(0.06)\end{array}$ \\
\hline Age $61-70$ & $\begin{array}{r}-0.25^{* * *} \\
(0.06)\end{array}$ & $\begin{array}{r}-0.18^{* * *} \\
(0.06)\end{array}$ & $\begin{array}{r}-0.41^{* * *} \\
(0.07)\end{array}$ & $\begin{array}{r}-0.32^{* * *} \\
(0.07)\end{array}$ \\
\hline Age 71-80 & $\begin{array}{r}-0.49^{* * *} \\
(0.09)\end{array}$ & $\begin{array}{r}-0.41^{* * *} \\
(0.09)\end{array}$ & $\begin{array}{r}-0.68^{* * *} \\
(0.11)\end{array}$ & $\begin{array}{r}-0.53^{* * *} \\
(0.11)\end{array}$ \\
\hline Education (1 = some college) & $\begin{array}{r}0.18^{* * *} \\
(0.07)\end{array}$ & $\begin{array}{r}0.27^{* * *} \\
(0.07)\end{array}$ & $\begin{array}{r}0.04 \\
(0.07)\end{array}$ & $\begin{array}{r}0.12 \\
(0.07)\end{array}$ \\
\hline Gender dummy ( 1 = male $)$ & $\begin{array}{r}0.09^{* *} \\
(0.04)\end{array}$ & $\begin{array}{l}0.08^{*} \\
(0.04)\end{array}$ & $\begin{array}{r}0.03 \\
(0.46)\end{array}$ & $\begin{array}{l}0.003 \\
(0.05)\end{array}$ \\
\hline Per capita income (log form) & $\begin{array}{l}0.07^{* *} \\
(0.02)\end{array}$ & $\begin{array}{r}0.07^{* *} \\
(0.02)\end{array}$ & $\begin{array}{r}0.14^{* * *} \\
(0.03)\end{array}$ & $\begin{array}{r}0.22^{* * *} \\
(0.04)\end{array}$ \\
\hline High blood pressure dummy & & $\begin{array}{r}0.05 \\
(0.05)\end{array}$ & & $\begin{array}{r}-0.000 \\
(0.06)\end{array}$ \\
\hline Bronchitis dummy & & $\begin{array}{r}0.07 \\
(0.06)\end{array}$ & & $\begin{array}{r}0.10 \\
(0.08)\end{array}$ \\
\hline Cancer dummy & & $\begin{array}{r}-0.26^{* *} \\
(0.12)\end{array}$ & & $\begin{array}{l}-0.15 \\
(0.17)\end{array}$ \\
\hline Better health at age of 75 dummy $(=1)$ & & $\begin{array}{r}0.07 \\
(0.21)\end{array}$ & & $\begin{array}{r}0.10 \\
(0.28)\end{array}$ \\
\hline Buy commercial insurance with one's & & & & \\
\hline own money dummy $(=1)$ & & $\begin{array}{r}-0.36^{* * *} \\
(0.05)\end{array}$ & & $\begin{array}{r}-0.28^{* * *} \\
(0.06)\end{array}$ \\
\hline Jiujiang dummy & & $\begin{array}{r}0.22^{* * *} \\
(0.06)\end{array}$ & & $\begin{array}{r}0.31^{* * *} \\
(0.07)\end{array}$ \\
\hline Nanning dummy & & $\begin{array}{r}0.23^{* *} \\
(0.06)\end{array}$ & & $\begin{array}{r}0.26^{* *} \\
(0.07)\end{array}$ \\
\hline If the risk variable is 5 in 1000 reduction & $\begin{array}{r}-0.22^{* * *} \\
(0.04)\end{array}$ & $\begin{array}{r}-0.27^{* * *} \\
(0.04)\end{array}$ & $\begin{array}{r}-0.27^{* * *} \\
(0.05)\end{array}$ & $\begin{array}{r}-0.29^{* * *} \\
(0.05)\end{array}$ \\
\hline Shape parameter (ln_p) & $\begin{array}{r}0.39^{* * * *} \\
(0.02)\end{array}$ & $\begin{array}{r}0.43^{* * *} \\
(0.37)\end{array}$ & $\begin{array}{r}0.47^{* * *} \\
(0.05)\end{array}$ & $\begin{array}{r}0.50^{* * *} \\
(0.05)\end{array}$ \\
\hline Number of observations & 1020 & 1020 & 707 & 707 \\
\hline
\end{tabular}

Note: ${ }^{*}$ indicates significance at the $10 \%$ level; ${ }^{* *}$ indicates significance at the $5 \%$ level; ${ }^{* * *}$ indicates significance at the $1 \%$ level. The reference base for city dummy is Shanghai; for age it is under 50 . Standard error in parentheses. 
pooled. ${ }^{3}$ Based on separate regressions for 5 in 1000 and 10 in 1000 risk reductions, the income elasticity of WTP is 0.22 for the 5 in 1000 risk reduction case and 0.30 for the 10 in 1000 risk reduction case. Guo and Hammitt (2009) report income elasticities of 0.16 for Beijing, 0.2 for urban Anqing and 0.6 for rural Anqing. Wang and Mullahy (2006) report an income elasticity of 1.42 for China based on surveys in Chongqing. Alberini et al. (2004) report income elasticities of WTP for U.S. respondents ranging from 0.26 to 0.33 for 5 in 1000 risk reduction based on different model specifications.

Both gender (being male) and having at least some college education are positive and significant for screening approach A, but not for screening approach B. Differences among cities are highly significant, even after controlling for income, education, and health.

We also test for the effects of age on WTP for mortality risk reductions (Krupnick, 2007; Brey \& Pinto-Prades, 2017; Robinson \& Hammitt, 2016). We find that WTP declines with age. In both screening approaches A and B, coefficients for all age categories over 50 are negative relative to respondents aged 50 and under, and highly significant. We only observe responses of individuals from 40 to 80 years of age. Over this age range, we find a concave relationship between age and WTP, with the steepness of the downward slope increasing with age. This result is robust across model specifications and screening approaches.

Experience with health and individuals' degree of financial risk aversion would be expected to influence WTP to reduce mortality risk. Some studies using this basic survey instrument find health effects to be significant (Krupnick \& Alberini, 2000; Alberini et al., 2004). We examined the influence of personal and family experience with a variety of illnesses on WTP, but the only influence of health on WTP we found was for respondents who had personally had cancer. These respondents were willing to pay less for the mortality risk reduction than those who had not had cancer. This result was significant only for screening approach A. We also found that after controlling for differences in income and other covariates, respondents who purchased commercial insurance, which we included as a measure of financial risk aversion, had a lower WTP for mortality risk reduction than those who did not. This result was robust to the screening approach used.

\footnotetext{
3 The Weibull regression assumed that WTP $=\exp \left(x_{i} \beta\right) \mathrm{WTP}_{0}^{1 / \theta}$. A $\log$ transformation produces the equation $\log \mathrm{WTP}=x_{i} \beta+(1 / \theta) \log \mathrm{WTP}_{0}$, where $\log \mathrm{WTP}_{0}$ follows the type I extreme value distribution. If we log income in the regression, then the coefficient of income variable measures the elasticity of income. Of the three regions, Nanning has the highest income elasticity (0.19), followed by Jiujiang $(0.23)$, and then by Shanghai $(0.26)$.
} 


\subsection{Willingness to pay for delayed risk reductions}

We also estimate WTP for delayed risk reductions for respondents aged 40-60. The pooled WTP estimate for a delayed risk reduction of 5 in 1000 over 10 years starting at age 70 ranges from 466 yuan per year for the screening approach A, lower Turnbull model to 565 yuan per year for the screening approach B, Weibull model (Table 4). Comparisons across cities are not robust to the screening approach. With screening approach A, WTP in Shanghai is statistically higher than in Nanning and Jiujiang. With screening approach B, WTP values in Shanghai and Jiujiang are similar and statistically lower than WTP in Nanning.

By comparing WTP estimates for the same risk reduction, but either contemporaneous or delayed, we can examine whether this delay resulted in a lower WTP, which is evidence for the use of discounting. The results from Nanning and Jiujiang show statistically significant discounting for all models except the lower Turnbull screening approach B. The Shanghai results do not show statistically significant discounting in the lower Turnbull model and mixed results with the Weibull model. Pooled data show strongly significant discounting with all models and both screening approaches (Table 4).

\section{Payment screen cursor analysis to test for anchoring bias}

The payment screen approach provides a unique opportunity to study how the structure of a PC affects respondents' behavior, because cursor movements can be digitally recorded. We recorded the initial, randomly assigned, cursor location for each respondent, their final choice, and the length of time they spent on each payment screen. Table 6 presents several variables created in order to describe how respondents moved around the payment screen from initial to final cursor placement. Use of these variables allows us to test for starting point bias and for level of engagement in the survey.

Starting point bias involves respondents anchoring on an initial bid, in this study the initial random cursor placement. Constraint in movement from the initial cursor placement is a necessary, but not sufficient, condition for starting point bias. For some respondents, the initial cursor placement is their true WTP. The default probability that a randomly placed cursor would appear over an individual's true WTP is $1 / 25$ or $4 \%$. With 25 possible cells (five rows and five columns) over which the cursor could appear, the probability that the cursor would appear in the same row or column as the individual's true WTP is $1 / 5$ or $20 \%$. Vertical move- 
Table 6 Variables used in analysis of payment screen cursor movement.

\begin{tabular}{ll}
\hline Variable name & Variable definition \\
\hline Cursor starting point & Initial $x, y$ coordinates on the payment screen matrix \\
Cursor ending point & $x, y$ coordinates associated with the final chosen WTP. \\
Absolute cursor movement & $\begin{array}{l}\text { Sum of the absolute horizontal and vertical distance between the cursor } \\
\text { starting and ending point. This ranges from } 0 \text { to } 8 .\end{array}$ \\
Relative cursor movement & $\begin{array}{l}\text { Actual absolute cursor movement as a percentage of total maximum } \\
\text { possible absolute vertical plus horizontal movement from randomly } \\
\text { assigned starting point. }\end{array}$ \\
\hline
\end{tabular}

ment between rows generally implies a greater numerical change than horizontal movements within rows.

T-test results suggest some evidence of anchoring: $9.5 \%$ of respondents did not move their cursor at all (nonmovers) compared with the expected 4\%; this difference is statistically significant. Only slightly fewer respondents moved out of their assigned row or column than expected (19\% did not move vertically and $18 \%$ did not move horizontally compared with the expected $20 \%$ ).

The amount of time respondents spend on the survey may be evidence of lack of engagement. We find no statistical difference in the length of time spent on the survey by those who fail to move the cursor according to one of our three definitions and those who do. It is possible that people with a lack of cursor movement are those who would get dropped for other reasons. We tested this hypothesis for each of the three ways in which respondents might "not move" from where the cursor was randomly assigned. Those who did not move at all from their randomly assigned cursor position were statistically more likely to be dropped from the sample under screening approach B than others. Those who moved horizontally, but not vertically, or who moved vertically, but not horizontally, were no more likely than others to be dropped from the sample. We found few other statistically significant relationships between each of the individual criteria for dropping respondents and any of the variables describing a lack of movement from the initial cursor position.

We also tested the hypothesis that personal characteristics of nonmovers are different from those of movers. The only statistically significant difference we found was that a higher percentage of respondents from Jiujiang (12\%) were nonmovers than respondents in Nanning (9\%) or Shanghai (7\%). For all but one debriefing question, there was no statistically significant difference between movers and nonmovers. Those who did not believe the probability of dying given their age and gender applied to them were also more likely not to move the cursor than those who did believe the probability of dying provided on the basis of population 
mortality statistics. This may indicate that these respondents were not "buying into" the survey.

The critical question is whether the cursor starting point affects WTP. We tested for equality of WTP between movers and nonmovers using an F-test, a WilcoxonMann-Whitney test, a Kruskal-Wallis test, a Kolmogorov-Smirnov test, and a median score test. None of these tests shows a difference in WTP between movers and nonmovers.

Table 7 presents regression analyses examining the influence of cursor movement on WTP for current risk reductions. The regressions include variables that are generally found to explain WTP as well as the randomly assigned starting value. The random cursor placement coefficients are statistically significant for both the lower Turnbull and Weibull models with screening approach A, but insignificant for the Weibull model for the preferred screening approach B. Using the lower Turnbull model, an increase in the starting value of one yuan results in an increase in WTP of 0.1 yuan - a $10 \%$ bias. With the preferred screening approach B, this bias is $5 \%$. In the preferred Weibull model, the effect is significant for screening approach A, but very small, and zero for preferred screening approach B. That is, a higher starting point value tends to be associated with a higher WTP. This effect is greater when WTP is assumed to be the value immediately below the chosen WTP (lower Turnbull model) than when chosen WTP is assumed to represent the upper end of an interval between the chosen WTP and the next lower value on the payment screen (Weibull model).

To sum up, while there is evidence that more nonmovers were observed in the study than would be expected with completely random behavior taken as a whole, and we see some evidence of starting point bias influencing WTP, the effect ranges from zero for the preferred screening method and model to $10 \%$ for the less preferred model. It is also worth noting that we found sizable percentages of respondents who choose round numbers in the matrix (such as 100 and 1000). To counter this well-known tendency (Pope \& Simonsohn, 2011; Lynn, Masaki Flynn $\&$ Helion, 2013), perhaps PCs should be constructed without round numbers.

\section{Comparisons with results from other countries using the same survey}

Table 8 reports selected results from the eight studies using essentially the same survey instrument as we used in China, with a few exceptions as noted above. For comparability purposes, Table 8 presents results from Weibull models and a contemporaneous (or latent) 5/1000 risk reduction over the next 10 years. All values 
Table 7 Regressions on WTP on the first WTP question for current risk reduction with random starting WTP value.

\begin{tabular}{|c|c|c|c|c|}
\hline \multirow[b]{2}{*}{ Variable } & \multicolumn{2}{|c|}{ Lower Turnbull } & \multicolumn{2}{|c|}{ Weibull } \\
\hline & Screening A & Screening B & Screening A & Screening B \\
\hline \multirow[t]{2}{*}{ Intercept } & $756.08^{* * *}$ & 559.52 & $7.13^{* * *}$ & $6.66^{* * *}$ \\
\hline & $(252.70)$ & $(389.52)$ & $(0.26)$ & $(0.44)$ \\
\hline \multirow[t]{2}{*}{ Random starting WTP cursor placement } & $0.10^{* * *}$ & $0.05^{*}$ & $0.0001^{* * *}$ & 0.00002 \\
\hline & $(0.02)$ & $(0.03)$ & $(0.00)$ & $(0.00)$ \\
\hline \multirow[t]{2}{*}{ Age } & $-8.41^{* * *}$ & $-12.68^{* * *}$ & $-0.011^{* * *}$ & $-0.02^{* * *}$ \\
\hline & $(1.95)$ & $(2.42)$ & $(0.00)$ & 0.00 \\
\hline \multirow[t]{2}{*}{ Some college } & $146.89^{* *}$ & 57.56 & $0.21^{* * *}$ & 0.08 \\
\hline & $(59.15)$ & $(68.33)$ & $(0.07)$ & $(0.08)$ \\
\hline \multirow[t]{2}{*}{ Per capita income (000 yuan) } & $40.31^{* *}$ & $81.56^{* *}$ & 0.03 & $0.10^{* *}$ \\
\hline & $(19.49)$ & $(31.87)$ & $(0.02)$ & 0.04 \\
\hline \multirow[t]{2}{*}{ Good/excellent present health dummy } & 7.85 & 41.79 & 0.05 & 0.08 \\
\hline & (37.76) & $(44.76)$ & $(0.04)$ & $(.05)$ \\
\hline \multicolumn{5}{|l|}{ Buy commercial insurance with one's } \\
\hline \multirow[t]{2}{*}{ own money dummy } & $-247.04^{* * *}$ & $-121.87^{* *}$ & $-0.33^{* * *}$ & $-0.26^{* * *}$ \\
\hline & (43.13) & $(55.16)$ & $(0.05)$ & $(0.06)$ \\
\hline \multirow[t]{5}{*}{ Risk 5} & $-195.44^{* * *}$ & $-242.89^{* * *}$ & $-0.25^{* * *}$ & $-0.30^{* * *}$ \\
\hline & $(35.59)$ & 42.07 & $(0.04)$ & $(0.05)$ \\
\hline & \multicolumn{2}{|c|}{ LR chi2 (pr. > chi2) } & \multicolumn{2}{|c|}{ Scale } \\
\hline & $138.62^{* * *}$ & $89.77^{* * *}$ & $0.43^{* * *}$ & $0.50^{* * *}$ \\
\hline & $(0.00)$ & 0.00 & $(0.02)$ & $(0.03)$ \\
\hline $\mathrm{N}$ & 1010 & 677 & & \\
\hline
\end{tabular}

Note: ${ }^{*}$ indicates significance at the $10 \%$ level; ${ }^{* *}$ indicates significance at the $5 \%$ level; ${ }^{* * *}$ indicates significance at the $1 \%$ level. The reference base for city dummy is Shanghai; for age it is under 50 . Standard errors in parentheses.

are converted to \$US using PPP exchange rates in the year of the survey and then adjusted to 2016 dollars using the U.S. All Items Urban Consumer Price Index (CPI). Both internal and external scope tests were passed in China, Canada, the United States, Japan, and Mongolia. Modifications to the survey design used in the U.K., France, and Italy did not permit an external scope test. The World Bank classified both Mongolia and China as lower middle income countries at the time surveys were fielded in each country (World Bank, 2017). All other countries where this survey was fielded were classified as high income countries. 
Table 8 Mean VSL by country and study using the 5 in 10,000 annual risk change and Weibull model (\$US figures obtained with PPP conversions and CPI adjustment to 2016).

\begin{tabular}{|c|c|c|c|c|c|c|c|c|}
\hline & $\begin{array}{r}\text { China* } \\
\text { Shanghai, } \\
\text { Jiujiang, Nanning }\end{array}$ & $\begin{array}{r}\text { Canada } \\
\text { Hamilton, } \\
\text { Ontario }\end{array}$ & $\begin{array}{r}\text { United States } \\
\text { Entire } \\
\text { country }\end{array}$ & $\begin{array}{r}\text { Japan } \\
\text { Shizuoke }\end{array}$ & $\begin{array}{r}\text { U.K. } \pm \\
\text { Bath }\end{array}$ & $\begin{array}{r}\text { France } \pm \\
\text { Strasbourg }\end{array}$ & $\begin{array}{r}\text { Italy } \pm \\
\text { Five cities }\end{array}$ & $\begin{array}{r}\text { Mongolia* }^{*} \\
\text { Ulaanbaatar }\end{array}$ \\
\hline $\begin{array}{l}\text { WTP (current } 5 \text { in 1000) } \\
\text { as a \% of mean household } \\
\text { income }\end{array}$ & $1.49 \%$ & $1.00 \%$ & $1.45 \%$ & $0.81 \%$ & $1.59 \%$ & $7.71 \%$ & $3.50 \%$ & $3.3 \%$ \\
\hline $\begin{array}{l}\text { Current VSL: } 5 / 1000 \text { \$US } \\
\text { (millions) }\end{array}$ & $0.61^{* *}$ & 1.04 & 1.72 & 0.74 & 1.31 & 5.09 & 2.55 & 0.64 \\
\hline $\begin{array}{l}\text { Scope test: ratio of WTP } \\
\text { values for } 10 \text { versus } 5 \text { in } \\
1000 \text { changes }\end{array}$ & 1.3 & 1.3 & 1.6 & 1.5 & NA & NA & NA & 1.15 \\
\hline $\begin{array}{l}\text { Future VSL: } 5 / 1000 \text { \$US } \\
\text { (millions) }\end{array}$ & 0.47 & 0.59 & 0.77 & 0.54 & 0.57 & 1.40 & 0.97 & 0.45 \\
\hline $\begin{array}{l}\text { Ratio of future to contem- } \\
\text { poraneous VSL }\end{array}$ & 0.77 & 0.57 & 0.45 & 0.73 & 0.44 & 0.27 & 0.38 & 0.70 \\
\hline
\end{tabular}

*Payment screen elicitation. All other surveys use DC elicitation.

\pm Scope tests were not conducted.

** In \$US 2016, the Chinese VSL for a current risk reduction is $\$ 614,805$ and for a future risk reduction is $\$ 471,963$. 
Table 8 reports mean WTP for a 5 in 1000 contemporaneous risk reduction as a percentage of mean household income. The value for China, $1.49 \%$, is roughly comparable to that in the United States and the U.K. (1.45\% and $1.59 \%$, respectively). The values for France, Mongolia, and Italy are higher and cover a larger range $(3.3 \%-7.7 \%)$.

China has the lowest VSL for the contemporaneous 5 in 1000 risk reduction (\$0.61 million); slightly lower than that for Mongolia, the other developing country in which the survey was conducted. ${ }^{4}$ The contemporaneous VSL for Japan is also low (\$0.74 million). China also has the lowest VSL for a future risk reduction of the same magnitude ( $\$ 0.47$ million), again, roughly comparable to Ulaanbaatar, Mongolia and only slightly less than Japan and the U.K.

The Chinese cities have the highest ratio of future to current VSL (0.77), driven primarily by Shanghai. All three Asian countries have high ratios (0.70-0.77) compared with the western countries $(0.27-0.57)$. The results suggest that the Chinese may be more future oriented than people from other countries - a result in line with reported household savings rates in urban China of nearly $30 \%$ compared with savings rates in western countries of close to zero or even negative (Horioka \& Wan, 2006).

With all of the studies in Table 8 put into (nearly) comparable terms, we can begin to examine the efficacy of using benefits transfers by comparing such transferred estimates with the actual VSL estimates from the country itself. Benefits transfers are performed by taking a VSL from a "study site" and transferring it to a "policy site." The transfer itself can be performed in a number of ways, but the most prevalent is to base the transfer on income differentials across countries (see, e.g., Hammitt \& Robinson, 2011 and papers in this symposium). The studies cited in Table 8, as well as a long history of research underlying national VSL estimates, show that WTP to reduce risk is sensitive to income (Lindhjem, Navrud, Axel Braathen \& Biausque, 2011), but also to cultural, demographic, and other factors that may differ across countries. The influence of these nonincome factors suggests that transfers based solely on income differentials may not provide entirely accurate assessments of policy site preferences for mortality risk reduction. Estimates of WTP using primary research in different countries, as reported in Table 8, reflect differences in both income and non-income influences on WTP to reduce mortality risk and thus can provide some insight into the importance of considering nonincome influences in benefits transfer.

\footnotetext{
4 As with our Chinese study, the Mongolian study only surveyed people living in an urban area, Ulaanbaatar. Ulaanbaatar is Mongolia's capital and by far its largest city. With a population of 1.3 million in 2013, Ulaanbaatar accounts for slightly less than a third of the national population (National Statistics Office of Mongolia 2017).
} 
Formally, WTP for risk reduction, expressed in inverted demand form, is a function of the risk reduction, real income, and prices of other goods, holding other influences constant, i.e., $\mathrm{WTP}_{i}(r)=f\left(r, P_{i}, Y_{i} ; Q_{i}\right)$. If risk reduction is a normal good, then countries with higher real incomes should have higher VSLs than countries with lower real incomes, all else being equal. ${ }^{5}$ Typically, the percentage difference in VSLs between the study and policy site countries is assumed to be proportional to the percentage difference in real incomes, meaning that what we refer to as the transfer elasticity equals one. We use the term transfer elasticity to distinguish it from a standard income elasticity of WTP for mortality risk reductions, which is usually estimated in a regression of income on WTP within a country. ${ }^{6}$ Hammitt and Robinson (2011), Narain and Sall (2016), and Viscusi and Masterman in this issue review the use of such transfer elasticities. Recent work by the World Bank (i.e., Narain \& Sall, 2016; World Bank, 2016) assumes that the income elasticity to use for transferring a U.S. or other developed country VSL to a developing country (low or middle income) is greater than 1.0, specifically 1.2, while the elasticity to transfer between developed countries is assumed to be 0.8 .

Because we have estimated a VSL in a number of possible "policy and study countries" using essentially the same survey, we can compare these estimates with transferred VSL values and test the accuracy of the above assumptions. The first section of Table 9 presents income estimates both for the year the study was conducted and for 2015 converted to U.S. dollars using PPP adjustment factors. The most recent year for which there are internationally comparable estimates of real gross national income (GNI) per capita is 2015. The second section of Table 9 presents VSL estimates for each country cited in Table 8 adjusted to \$US 2015. The second row of the second section of Table 9 presents the implied transfer elasticities - i.e., the ratio of the percentage difference between the empirically estimated VSL for each country of interest and the United States relative to the percentage difference between GNI per capita in each country and the U.S. GNI per capita. These empirical estimates range from -4.89 in France to 2.17 in Japan; the estimate for China is 0.90 and that for Mongolia is 0.88 . These ratios are consistently different from one; those for our two lower income countries are less than, not greater than, one, in contrast to that suggested in the World Bank analysis. The third row of the second section of Table 9 makes these comparisons more explicit by showing what

5 For more on this topic, see other papers in this issue, particularly Hammitt as well as Viscusi and Masterman in this symposium.

6 The basic elasticity relationship of percentage change of one variable of interest, here VSL, in response to a percentage change in the other variable, here income, can be solved for the variable of interest, here VSL, in either discrete, $\mathrm{VSL}_{1}=\mathrm{VSL}_{0}(1+\varepsilon * \%$ change in income), or continuous form, $\mathrm{VSL}_{1}=\mathrm{VSL}_{0}\left(\mathrm{Inc}_{1} / \mathrm{Inc}_{0}\right)^{\varepsilon}$. Empirically, estimates based on the two approaches can differ when the elasticity or change in income is large. We use discrete estimates. 
Table 9 Impact on benefits transfer of adjusting for inflation only versus adjusting for inflation and income growth: mean VSL by country and study using the 5 in 10,000 annual risk change and the Weibull model.

\begin{tabular}{|c|c|c|c|c|c|c|c|}
\hline & China* & United States & Japan & UK & France & Italy & Mongolia \\
\hline \multicolumn{8}{|l|}{ Income } \\
\hline Year survey conducted & 2006 & 2000 & 1999 & 2002 & 2002 & 2002 & 2009 \\
\hline Study year real GNI per capita (constant 2011 \$US)* & 9313 & 46,267 & 33,433 & 34,951 & 35,825 & 37,030 & 7082 \\
\hline 2015 real GNI per capita (constant 2011 \$US) & 10,932 & 53,442 & 39,313 & 37,975 & 38,399 & 34,028 & 10,851 \\
\hline \multicolumn{8}{|l|}{ Adjusting for inflation } \\
\hline 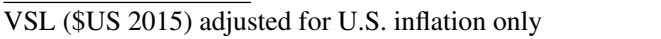 & 608,388 & $2,119,512$ & 904,660 & $1,292,727$ & $5,038,322$ & $2,519,161$ & 624,266 \\
\hline Estimated transfer elasticity & 0.90 & NA & 2.17 & 1.35 & -4.89 & -0.52 & 0.88 \\
\hline $\begin{array}{l}\text { VSL (\$US 2015) if transfer elasticity }=1 \text { and the U.S. } \\
\text { VSL estimate is transferred }\end{array}$ & 433,555 & $2,119,512$ & $1,559,158$ & $1,506,073$ & $1,522,907$ & $1,349,558$ & 419,641 \\
\hline \multicolumn{8}{|l|}{ Adjusting for inflation and income growth } \\
\hline VSL (\$US year survey conducted) & 517,514 & $1,540,000$ & 635,934 & 981,273 & $3,824,448$ & $1,912,224$ & 565,000 \\
\hline Income elasticity of household WTP from regressions & 0.22 & 0.33 & 0.41 & 0.51 & 0.51 & 0.51 & 0.60 \\
\hline $\begin{array}{l}\text { \% Change in real GNI per capita (\$US 2011) from } \\
\text { year survey conducted to } 2015^{*}\end{array}$ & 17.4 & 15.5 & 17.6 & 8.7 & 7.2 & -8.1 & 49.4 \\
\hline Estimated transfer elasticity & 0.85 & NA & 2.13 & 1.39 & -4.88 & -0.24 & 0.76 \\
\hline VSL (\$US 2015) adjusted for inflation and income growth & 631,651 & $2,227,982$ & 969,900 & $1,349,772$ & $5,222,946$ & $2,415,009$ & 809,343 \\
\hline
\end{tabular}

Transfer elasticity $=(\%$ difference between VSL in United States and study country $) /(\%$ difference between GNI/capita in United States and study country). Income elasticity of household WTP is the estimated income elasticity of demand taken from construct validity regressions in each study.

${ }^{*}$ International price adjustments are conducted using PPP factors to adjust to U.S. dollars. Source: World Development Indicators: Table 4.16. Exchange rates and prices; World Development Indicators: size of the economy; PPP GNI per capita in 2015. Income is taken from World Bank, GNI per capita, PPP (constant 2011 international \$), accessed at http://data.worldbank.org/indicator/NY.GNP.PCAP.PP.KD. Chinese income calculated from 2011 Chinese GNI per capita, PPP and Chinese PP estimates for 2006, 2011 and 2015, based on World Bank methods for extrapolating PPP estimates, https://datahelpdesk.worldbank.org/kno wledgebase/articles/665452-how-do-you-extrapolate-the-ppp-conversion-factors, accessed May 15, 2016.

** Inflation adjustment made using U.S. All Items Urban CPI. 
the $\$ 2015$ VSLs would be in each country were one transferring U.S. VSLs to each country under the assumption that the transfer elasticity is 1.0. The differences in these VSL estimates are substantial.

Over time, real income within a country may change. Where changes in real income are substantial, it becomes important to reflect the responsiveness of WTP to income in VSL estimates. Major U.S. regulatory agencies include such updating for real income growth, based on estimates of the income elasticity of WTP for mortality risk reduction in the United States or on assumptions, as part of their standard adjustment of the VSL used in their regulatory impact analyses (see Hammitt \& Robinson, 2011). ${ }^{7}$ In the third section of Table 9, we present income elasticities of WTP estimated for each of the countries where this survey was conducted except Canada, where the form of the income variable did not permit estimation of a comparable income elasticity. These income elasticities reflect the responsiveness of WTP estimates to income differences within each study country. This is the conventional concept of an income elasticity of WTP for mortality risk reduction. Both China and Mongolia have experienced significant real income growth in recent years (Table 9). Thus, failure to account for such growth biases estimated VSLs downwards. In Table 9, we compare "inflation adjusted" and "inflation and income growth adjusted" VSLs. In the case of Mongolia, the VSL is $30 \%$ higher when responsiveness to real income growth is taken into account. A lower row of Table 9 shows the effect of taking real income growth into account on transfer elasticities. When this is done, the transfer elasticities for China and Mongolia fall, further widening the gap between them and the assumed transfer elasticity appearing in the literature of 1.0 (or even 1.2).

\section{Conclusion}

Standard practice in estimating mortality benefits from pollution policies in countries where no in-country estimates are available or are of insufficient quality is to assume that the VSL from the policy site is proportional to the VSL from the

\footnotetext{
7 DOT and HHS now use elasticities of 1.0, EPA uses a range. See U.S. Environmental Protection Agency, 2015, BenMAP: Environmental Benefits Mapping and Analysis Program - Community Edition User's Manual, prepared for the Office of Air Quality Planning and Standards by RTI International (http://www2.epa.gov/sites/production/files/2015-04/documents/benmap-ce_user_manual_march 2015.pdf). U.S. Department of Health and Human Services, 2016, Guidelines for Regulatory Impact Analysis (https://aspe.hhs.gov/pdf-report/guidelines-regulatory-impact-analysis), (Primer: https://aspe. hhs.gov/pdf-report/guidelines-regulatory-impact-analysis-primer). U.S. Department of Transportation, 2016, Guidance on Treatment of the Economic Value of a Statistical Life (VSL) in Departmental Analyses - 2016 Adjustment (http://www.dot.gov/regulations/economic-values-used-in-analysis).
} 
study site based on their difference in income (a transfer elasticity of 1.0). Certainly this approach is preferable to an alternative approach that assumes that the VSL is identical in all countries. The latter approach would result in unrealistically high ratios of the VSL to the real GNI per capita and would likely be much higher than mitigation costs, biasing toward too much cleanup. At the same time, preferences for reducing risk of death may well have a lot to do with cultural differences and other factors beyond income differences. Therefore, assuming, as is standard practice, that transfer elasticities are around 1.0 may not reflect underlying preferences, under- or over-estimating the VSL.

It is usually difficult to test these propositions because studies estimating the VSL in one country are so different from those used in another country. The research reported on in this paper enables such a test because the same basic survey instrument was used to estimate the VSL in eight countries, including both developed and developing countries. This paper describes results from one of these studies conducted in China, adding the eighth country to the comparison.

Comparing across the eight countries in which this survey has been fielded, we see substantial difference in contemporaneous VSL estimates, ranging widely across countries from $\$ 614,805$ ( $\$$ US 2016) for China to $\$ 5.09$ million (\$US 2016) for France, adjusting for inflation only. Most contemporaneous VSL estimates range from $\$ 0.61$ to $\$ 2.55$ million (\$US 2016). Estimates of VSL for China and Mongolia, the two low to middle income countries in the set, are lower than they are for the six high income countries in absolute terms, but not as a percentage of mean household income. Willingness to pay for future risk reduction is lower than WTP for current risk reduction in all countries. China, Mongolia, and Japan are future oriented, with ratios of future to contemporaneous VSLs of $0.70-0.77$, compared with western countries which have ratios of 0.27-0.57.

Using the contemporaneous VSL estimates and income differences across countries in our sample, it is clear that the VSLs computed using a transfer elasticity of 1.0 do not match up well with VSLs estimated directly. Interestingly, the percentage difference between the U.S. VSL and the Mongolian or Chinese VSL estimates is only slightly less than proportional to the income differences of these countries with the United States ( 0.88 and 0.90, respectively) when VSL estimates are only adjusted for inflation, but these transfer elasticities become smaller when the VSLs are adjusted for income growth in each country before the comparison is made. These results reinforce the need for more VSL studies in low and middle income countries to strengthen the empirical basis for benefits transfer to low and middle income countries.

Finally, our study in China gave us the opportunity to use a payment "screen" (an electronic and more flexible version of the payment card approach) as a new 
type of method for elicitation of WTP. It has been suggested in the literature that elicitation using payment cards works better in terms of passing scope tests in developing countries than elicitation using a dichotomous choice approach. Our experience supports this argument. While we find some evidence of starting point bias in the sense of less movement from the starting point than would be expected randomly, we find no statistical difference in WTP between participants who moved their cursor from the starting point and those who did not.

Acknowledgments and Disclaimer: We would like to acknowledge the financial assistance of the World Bank's Asian Department, as well as a grant from the Beijing government. The faith, guidance, and insights of our project officer, Jostein Nygard, Team Leader at the World Bank, are gratefully acknowledged, along with advice from members of the Environmental Cost Model team, particularly Maureen Cropper, and both advice and work of the participating Chinese institutions, including Dr. Xizhe Peng and his staff at Fudan University, Shanghai, who helped to design and program the survey as well as administer one round in Shanghai, and Dr. Xiangang Zeng and his staff at Renmin University, Beijing, who administered much of the survey. Finally, a series of research assistants at RFF deserve much credit, including Michael McWilliams and Gina Waterfield. The views expressed herein are those of the author(s) and do not necessarily reflect the views of the Economic Research Service or U.S. Department of Agriculture.

\section{References}

Alberini, Anna, Cropper, Maureen, Krupnick, Alan \& Simon, Natalie (2004). Does the Value of Statistical Life Vary with Age and Health Status? Evidence from the U.S. and Canada. Journal of Environmental Economics and Management, 48, 769-792.

Alberini, Anna, Cropper, Maureen, Krupnick, Alan \& Simon, Natalie (2006a). Willingness to Pay for Mortality Risk Reductions: Does Latency Matter? Journal of Risk and Uncertainty, 32, 231-245.

Alberini, Anna, Hunt, Alistair \& Markandya, Anil (2006b). Willingness to Pay to Reduce Mortality Risks: Evidence from a Three-country Contingent Valuation Study. Environmental and Resource Economics, 33(2), 251-264.

Arrow, Kenneth, Solow, Robert, Portney, Paul, Leamer, Edward, Radner, Roy \& Schuman, Howard (1993). Report of the NOAA Panel on Contingent Valuation. Federal Register, 58(10), 4601-4614.

Aunan, Kristin, Berntsen, Terje, O'Connor, David, Hindman Persson, Therese, Vennemo, Haakon \& Zhai, Fan (2007). Benefits and Costs to China of a Climate Policy. Environment and Development Economics, 12(3), 471-497.

Aunan, Kristin, Fang, Jinghua, Vennemo, Haakon, Oye, Kenneth \& Seip, Hans M. (2004). Co-Benefits of Climate Policy - Lessons Learned from a Study in Shanxi, China. Energy Policy, 32(4), 567-581. 
Aunan, Kristin \& Wang, Shuxiao (2014). Internal Migration and Urbanization in China: Impacts on Population Exposure to Household Air Pollution (2000-2010). Science of the Total Environment, 481, 186-195.

Blaine, Thomas, Lichtkopper, Frank, Jones, Keith \& Zondag, Randall (2005). An Assessment of Household Willingness to Pay for Curbside Recycling: A Comparison of Payment Card and Referendum Approaches. Journal of Environmental Management, 76(1), $15-22$.

Blamey, Russell, Bennett, Jeff \& Morrison, Mark (1999). Yea-Saying in Contingent Valuation Surveys. Land Economics, 75, 126-141.

Bloom, David, Cafiero, Elizabeth, Jané-Llopis, Eva, Abrahams-Gessel, Shafika, Bloom, Lakshmi, Fathima, Sana, Feigl, Andrea, Gaziano, T., Mowafi, M., Pandya, A., Prettner, K., Rosenberg, L., Seligman, B., Stein, A. Z. \& Weinstein, C. (2012). The Global Economic Burden of Noncommunicable Diseases. Geneva, Switzerland: World Economic Forum.

Brey, Raul \& Pinto-Prades, Jose Luis (2017). Age Effects in Mortality Risk Valuation. The European Journal of Health Economics, 18(7), 921-932.

Brown, Tom, Champ, Patricia, Bishop, Richard \& McCollum, Daniel (1996). Which Response Format Reveals the Truth about Donations to a Public Good? Land Economics, 72(2), 152-166.

Brown, Phillip \& Huff, Thomas (2011). Willingness to Pay in China's New Cooperative Medical System. Contemporary Economic Policy, 29(1), 88-100.

Cao, Jing, Ho, Mun S. \& Jorgenson, Dale W. (2009). The Local and Global Benefits of Green Tax Policies in China. Review of Environmental Economics \& Policy, 3(2), 189-208.

Champ, Patricia \& Bishop, Richard (2006). Is Willingness to Pay for a Public Good Sensitive to the Elicitation Format? Land Economics, 82(2), 162-173.

Cropper, Maureen L. \& Sussman, Frances G. (1990). Valuing Future Risks to Life. Journal of Environmental Economics and Management, 19(2), 160-174.

Guo, Xiaping \& Hammitt, James (2009). Compensating Wage Differentials with Unemployment: Evidence from China. Environmental and Resource Economics, 42, 187-209.

Hammitt, James \& Robinson, Lisa (2011). The Income Elasticity of the Value per Statistical Life: Transferring Estimates between High and Low Income Populations. Journal of Benefit-Cost Analysis, 2(1), 1-29.

Hammitt, James K. \& Zhou, Ying (2006). The Economic Value of Air-Pollution-Related Health Risks in China: A Contingent Valuation Study. Environmental and Resource Economics, 33(3), 399-423.

Heinzen, Rebekah R. \& Bridges, John F. P. (2008). Comparison of Four Contingent Valuation Methods to Estimate the Economic Value of a Pneumococcal Vaccine in Bangladesh. International Journal of Technology Assessment in Health Care, 24(4), 481-487.

Hoffmann, Sandra, Qin, Ping, Krupnick, Alan, Badrakh, Burmaajav, Batbaatar, Suvd, Altangerel, Enkhjargal \& Sereeter, Lodoysamba (2012). The Willingness to Pay for Mortality Risk Reductions in Mongolia. Resource and Energy Economics, 34(4), 493-513.

Holmes, Thomas \& Randall, Kramer (1995). An Independent Sample Test of Yea-Saying and Starting Point Bias in Dichotomous-Choice Contingent Valuation. Journal of Environmental Economics and Management, 29(1), 121-132.

Horioka, Charles \& Wan, Junmin (2006). The determinants of household savings in China: a dynamic panel analysis of provincial data. NBER Working Paper 12723 (December). 
Itaoka, Kenshi, Krupnick, Alan, Akai, Makoto, Alberini, Anna, Cropper, Maureen \& Simon, Nathalie (2007). Age, Health, and the Willingness to Pay for Mortality Risk Reductions: A Contingent Valuation Survey of Shizuoka, Japan, Residents. Environmental Economics and Policy Studies, 8(3), 211-237.

Johnston, Robert J., Boyle, Kevin, Adamowicz, Wiktor (Vic), Bennett, Jeff, Brouwer, Roy, Ann Cameron, Trudy, Michael Hanemann, W., Haley, Nick, Ryan, Mandy, Scarpa, Ricardo, Tourangeau, Roger \& Vossler, Christian A. (2017). Contemporary Guidance for Stated Preference Studies. Journal of the Association of Environmental and Resource Economists, 4(2), 319-405.

Johnston, Robert, Rolfe, John, Rosenberger, Randall \& Brouwer, Roy (Eds.) (2015). Benefit Transfer of Environmental and Resource Values: A Guide for Researchers and Practitioners. New York, NY: Springer.

Jun-Peng, Luo \& Yong, He (2008). Application of Contingent Valuation Method in Evaluation of Value of Statistical Life in Road Safety. Journal of Highway and Transportation Research and Development, 6, 130-134.

Kling, Catherine L., Phaneuf, Daniel J. \& Zhao, Jinhua (2012). From Exxon to BP: Has Some Number Become Better than No Number? The Journal of Economic Perspectives, 26(4), 3-26.

Krupnick, Alan (2007). Mortality-Risk Valuation and Age; Stated Preference Evidence. Review of Environmental Economics and Policy, 1(2), 261-282.

Krupnick, Alan \& Alberini, Anna (2000). Cost of Illness and WTP Estimates of the Benefits of Improved Air Quality in Taiwan. Land Economics, 76(1), 37-53.

Krupnick, Alan, Alberini, Anna, Cropper, Maureen, Simon, Natalie, O’Brien, Bernie, Goeree, Ron \& Heintzelman, Martin (2002). Age, Health and the Willingness to Pay for Mortality Risk Reductions: A Contingent Valuation Study of Ontario Residents. Journal of Risk and Uncertainty, 24, 161-186.

Landrigan, Philip J. (2017). Air Pollution and Health. The Lancet Public Health, 2(1), e4-e5.

Li, Jichen (2015). Regional Differences in Life Expectancy in Mainland, China. Thesis, School of Risk and Actuarial Studies, Business School, University of New South Wales, Sydney, Australia.

Li, Y., Bai, M., Zhang, W., Yang, K. \& Wang, X. (2002). Analysis on the Influence Factors of Residents' Willingness to Pay for Improving Air Quality in Beijing. China Population Resources and the Environment, 12(6), 123-126.

Lindhjem, Henrik, Navrud, Ståle, Axel Braathen, Nils \& Biausque, Vincent (2011). Valuing Mortality Risk Reductions from Environmental, Transport, and Health Policies: A Global Meta-Analysis of Stated Preference Studies. Risk Analysis, 31(9), 1381-1407.

Liu, Wenge \& Zhao, Shengchuan (2013). The Value of Statistical Life in Road Traffic Based on Logit Model. Journal of Transportation Systems Engineering and Information Technology, 13(1), 137-141.

Lomborg, Bjørn (Ed.) (2013). Global Problems, Smart Solutions: Costs and Benefits. Cambridge, UK: Cambridge University Press.

Lu, Xingcheng, Yao, Teng, Fung, Jimmy C. H. \& Lin, Changqing (2016). Estimation of Health and Economic Costs of Air Pollution over the Pearl River Delta Region in China. Science of the Total Environment, 566, 134-143.

Lynn, Michael, Masaki Flynn, Sean \& Helion, Chelsea (2013). Do Consumers Prefer Round Prices? Evidence from Pay-What-You-Want Decisions and Self-Pumped Gasoline Purchases. Journal of Economic Psychology, 36, 96-102. 
Mead, Robert W. \& Brajer, Victor (2008). Environmental Cleanup and Health Gains from Beijing's Green Olympics. The China Quarterly, 194, 275-293.

Mitchell, Robert \& Carson, Richard (1981). An Experiment in Determining Willingness to Pay for National Water Quality Improvements: Draft Report to the U.S. Environmental Protection Agency, Washington, DC.

Mitchell, Robert \& Carson, Richard (1984). A Contingent Valuation Estimate of National Freshwater Benefits: Technical Report to the U.S. Environmental Protection Agency Washington, DC: Resources for the Future Press.

Mitchell, Robert Cameron \& Carson, Richard T. (1989). Using Surveys to Value Public Goods: The Contingent Valuation Method (pp. 240-241). Washington, DC: Resources for the Future Press.

Myers, Kelley, Parsons, George \& Edwards, Peter (2010). Measuring Recreational Use Value of Migratory Shorebirds on the Delaware Bay. Marine Resource Economics, 25(3), 247-264.

Narain, Urvashi \& Sall, Chris (2016). Methodology for Valuing the Health Impacts of Air Pollution: Discussion of Challenges and Proposed Solutions. Washington, DC: World Bank.

National Statistics Office of Mongolia (2015). Population and Housing. Census of Mongolia: National Report. Accessed at www.en.nso.mn/home, May 30, 2017.

Ohdoko, Taro, Komatzu, Satoru \& Kaneko, Shinji (2013). Residential Preferences for Stable Electricity Supply and a Reduction in Air Pollution Risk: A Benefit Transfer Study Using Choice Modeling in China. Environmental Economics and Policy Studies, 15, 309-328.

Organization for Economic Cooperation and Development (OECD) (2012). Mortality Risk Valuation in Environment, Health and Transport Policies. Paris: OECD Publishing.

Pope, Devin \& Simonsohn, Uri (2011). Round Numbers as Goals: Evidence from Baseball, SAT Takers, and the Lab. Psychological Science, 22(1), 71-79.

Ready, Richard, Buzby, Jean \& Hu, Dayuan (1996). Differences between Continuous and Discrete Contingent Value Estimates. Land Economics, 72, 397-411.

Ready, Richard, Navrud, Ståle \& Richard Dubourg, W. (2001). How Do Respondents with Uncertain Willingness to Pay Answer Contingent Valuation Questions? Land Economics, 77(3), 315-326.

Robinson, Lisa A. \& Hammitt, James K. (2016). Valuing Reductions in Fatal Illness Risks: Implications of Recent Research. Health Economics, 25(8), 1039-1052.

Rowe, Robert, Schulze, William \& Breffle, William (1996). A Test for Payment Card Biases. Journal of Environmental Economics and Management, 31, 178-185.

Ryan, Mandy, Scott, David \& Donaldson, Cam (2004). Valuing Health Care Using Willingness to Pay: A Comparison of the Payment Card and Dichotomous Choice Methods. Journal of Health Economics, 23(2), 237-258.

Shanghai Bureau of Statistics. Basic Statistics on National Population Census. http://www.s tats-sh.gov.cn/tjnj/nje11.htm?d1=2011tjnje/E0226.htm. Accessed June 27, 2017.

Smith, Richard (2006). It's Not Just What You Do, It's the Way That You Do It: The Effect of Different Payment Card Formats and Survey Administration on Willingness to Pay for Health Gain. Health Economics, 15(3), 281-293.

State Statistical Bureau of the People's Republic of China (2006). China Statistical Yearbook 2006. Beijing: China Statistical Information and Consultancy Service Center.

U.S. Department of Health and Human Services (2016). Guidelines for Regulatory Impact Analysis (https://aspe.hhs.gov/pdf-report/guidelines-regulatory-impact-analysis), 
(Primer:https://aspe.hhs.gov/pdf-report/guidelines-regulatory-impact-analysis-primer). Accessed June 27, 2017.

U.S. Department of Transportation (2016). Guidance on Treatment of the Economic Value of a Statistical Life (VSL) in Departmental Analyses - 2016 Adjustment (http://www.d ot.gov/regulations/economic-values-used-in-analysis). Accessed June 27, 2017.

U.S. Environmental Protection Agency (2015). BenMAP: Environmental Benefits Mapping and Analysis Program - Community Edition User's Manual, prepared for the Office of Air Quality Planning and Standards by RTI International (http://www2.epa.gov /sites/production/files/2015-04/documents/benmap-ce_user_manual_march_2015.pdf). Accessed June 27, 2017.

Viscusi, W. Kip, Huber, Joel \& Bell, Jason (2014). Assessing Whether There Is a Cancer Premium for the Value of a Statistical Life. Health Economics, 23(4), 384-396.

Viscusi, W. Kip \& Masterman, Clayton (2017). Income Elasticity and the Global Value of a Statistical Life. Journal of Benefit-Cost Analysis, 8(2), 226-250.

Wang, Hong \& Mullahy, John (2006). Willingness to Pay for Reducing Fatal Risk by Improving Air Quality: A Contingent Valuation Study in Chongqing, China. Science of the Total Environment, 367(1), 50-57.

Wang, Hua \& He, Jie (2014). Estimating the Economic Value of Statistical Life in China: A Study of the Willingness to Pay for Cancer Prevention. Frontiers of Economics in China, 9(2), 183-215.

Wang, Hua, He, Jie, Kim, Yoonhee \& Kamata, Takuya (2013). Willingness-to-pay for Water Quality Improvements in Chinese Rivers: An Empirical Test on the Ordering Effects of Multiple-Bounded Discrete Choices. Journal of Environmental Management, 131, 256-269.

Wang, Jiandong, Wang, Shuxiao, Scott Voorhees, A., Zhao, Bin, Jang, Carey, Jiang, Jingkun, Fu, Joshua S., Ding, Dian, Zhu, Yun \& Hao, Jiming (2015). Assessment of Short-Term PM 2.5-related Mortality Due to Different Emission Sources in the Yangtze River Delta, China. Atmospheric Environment, 123, 440-448.

Wang, Xiaoping \& Mauzerall, Denise (2006). Evaluating Impacts of Air Pollution in China on Public Health: Implications for Future Air Pollution and Energy Policies. Atmospheric Environment, 40, 1706-1721.

Welsh, Michael \& Poe, Gregory (1998). Elicitation Effects in Contingent Valuation: Comparisons to a Multiple Bounded Discrete Choice Approach. Journal of Environmental Economics and Management, 36, 170-185.

World Bank (2007). Cost of Pollution in China: Economic Estimates of Physical Damages. Washington, D.C.: World Bank.

World Bank (2017). World Bank Country and Lending Groups: historical classification by income in XLS format. https://datahelpdesk.worldbank.org/knowledgebase/articles/90 6519 (accessed April 7, 2017).

World Bank and Institute for Health Metrics and Evaluation (2016). The Cost of Air Pollution: Strengthening the Economic Case for Action. Washington, D.C: World Bank.

World Health Organization (2015). WHO Estimates of the Global Burden of Foodborne Diseases: Foodborne Disease Burden Epidemiology Reference Group 2007-2015. Geneva, Switzerland: World Health Organization.

Yang, Shang-Ho, Qing, Ping, Hu, Wuyang \& Liu, Yun (2013). Using a Modified Payment Card Survey to Measure Chinese Consumers' Willingness to Pay for Fair Trade Coffee: Considering Starting Points. Canadian Journal of Agricultural Economics/Revue Canadienne d'Agroeconomie, 61(1), 119-139. 
Yang, Xi, Teng, Fei \& Wang, Gehua (2013). Incorporating Environmental Co-Benefits into Climate Policies: A Regional Study of the Cement Industry in China. Applied Energy, 112, 1446-1453.

Yang, Zhao, Liu, Pan \& Xu, Xin (2016). Estimation of Social Value of Statistical Life Using Willingness-to-pay Method in Nanjing, China. Accident Analysis \& Prevention, 95, 308-316.

Zeng, Xian-gang \& Jiang, Yan (2010). Evaluation of Value of Statistical Life in Health Costs Attributable to Air Pollution. China Environmental Science, 2, 41. Accessed at: http://e n.cnki.com.cn/Article_en/CJFDTOTAL-ZGHJ201002041.htm, May 30, 2017.

Zhai, Guofang (2011). International Differences in Willingness to Pay for Reduced Risk Due to Risk Representation: Evidence from Cross-Country Surveys in Northeast Asia. Journal of Risk Research, 14(10), 1177-1190.

Zhang, Daisheng, Aunan, Kristin, Martin Seip, Hans, Larssen, Steinar, Liu, Jianhui \& Zhang, Dingsheng (2010). The Assessment of Health Damage Caused by Air Pollution and Its Implication for Policy Making in Taiyuan, Shanxi, China. Energy Policy, 38(1), 491-502.

Zhang, Xiao (2002). Valuing Mortality Risk Reductions Using the Contingent Valuation Method: Evidence from a Survey of Beijing Residents in 1999. Beijing, China: Centre for Environment and Development, Chinese Academy of Social Sciences.

Zhang, Yin \& Cai, Yun-long (2010). Measuring the Recreational Value of Jiuzhaigou Nature Reserve with Contingent Valuation Method. Economic Geography, 7, 29.

Zhao, Jun, Liu, Qiuxia, Lin, Liqing, Lv, Huafang \& Wang, Yao (2013). Assessing the Comprehensive Restoration of an Urban River: An Integrated Application of Contingent Valuation in Shanghai, China. Science of the Total Environment, 458, 517-526.

Zhongmin, Xu, Loomis, John, Zhigiang, Zhang \& Hamamura, Kuino (2006). Evaluating the Performance of Different Willingness to Pay Question Formats for Valuing Environmental Restoration in Rural China. Environment and Development Economics, 11(5), $585-601$. 